IZA DP No. 10126

Intergenerational Wealth Mobility and the Role of Inheritance: Evidence from Multiple Generations

Adrian Adermon

Mikael Lindahl

Daniel Waldenström

August 2016 


\title{
Intergenerational Wealth Mobility and the Role of Inheritance: Evidence from Multiple Generations
}

\author{
Adrian Adermon \\ IFAU, Uppsala University and UCLS \\ Mikael Lindahl \\ University of Gothenburg, CESifo, IFAU, IZA and UCLS \\ Daniel Waldenström \\ PSE, IFN, CEPR, IZA, UCLS and UCFS
}

Discussion Paper No. 10126

August 2016

IZA

P.O. Box 7240

53072 Bonn

Germany

Phone: +49-228-3894-0

Fax: +49-228-3894-180

E-mail: iza@iza.org

Any opinions expressed here are those of the author(s) and not those of IZA. Research published in this series may include views on policy, but the institute itself takes no institutional policy positions. The IZA research network is committed to the IZA Guiding Principles of Research Integrity.

The Institute for the Study of Labor (IZA) in Bonn is a local and virtual international research center and a place of communication between science, politics and business. IZA is an independent nonprofit organization supported by Deutsche Post Foundation. The center is associated with the University of Bonn and offers a stimulating research environment through its international network, workshops and conferences, data service, project support, research visits and doctoral program. IZA engages in (i) original and internationally competitive research in all fields of labor economics, (ii) development of policy concepts, and (iii) dissemination of research results and concepts to the interested public.

IZA Discussion Papers often represent preliminary work and are circulated to encourage discussion. Citation of such a paper should account for its provisional character. A revised version may be available directly from the author. 


\section{ABSTRACT \\ Intergenerational Wealth Mobility and the Role of Inheritance: Evidence from Multiple Generations*}

This study estimates intergenerational correlations in mid-life wealth across three generations, and a young fourth generation, and examines how much of the parent-child association that can be explained by inheritances. Using a Swedish data set we find parentchild rank correlations of $0.3-0.4$ and grandparents-grandchild rank correlations of $0.1-0.2$. Conditional on parents' wealth, grandparents' wealth is weakly positively associated with grandchild's wealth and the parent-child correlation is basically unchanged if we control for grandparents' wealth. Bequests and gifts strikingly account for at least 50 per cent of the parent-child wealth correlation while earnings and education are only able to explain 25 per cent.

JEL Classification: D31, J62

Keywords: multigenerational mobility, bequests, mid-life wealth

Corresponding author:

Mikael Lindahl

Department of Economics

University of Gothenburg

P.O.Box 640

40530 Gothenburg

Sweden

E-mail: Mikael.Lindahl@economics.gu.se

\footnotetext{
* The authors thank three anonymous referees, Wojciech Kopczuk, Magne Mogstad, Emmanuel Saez and Jan Stuhler, as well as numerous conference and seminar participants at ESPE 2015, ECINEQ 2015, OECD 2015, Schwanenverder 2015, Paris School of Economics 2016, Banca d'Italia 2015, Berkeley 2016, Canazei 2016 and Journées LAGV 2016. We also thank Malin Adermon, Eskil Forsell, Erika Karlenius, Arvid Olovsson, Per Sax Kaijser and Tamás Vasi for excellent research assistance. We also thank Sofia Sandgren Massih for the early work with the Malmö Data set. Adrian Adermon gratefully acknowledges financial support from the Jan Wallander and Tom Hedelius Foundation. Mikael Lindahl is a Royal Swedish Academy of Sciences Research Fellow supported by a grant from the Torsten and Ragnar Söderberg Foundations, Swedish Research Council and the European Research Council [ERC starting grant 241161]. Daniel Waldenström thanks the Swedish Research Council and the Jan Wallander and Tom Hedelius Foundation. Swedbank has provided financial support for the construction of the data set.
} 
This paper studies the persistence of wealth status across multiple generations and how much of the intergenerational persistence that is driven by direct inheritances from parents to their children. A voluminous empirical literature has studied the intergenerational mobility of incomes (see Solon, 1999, and Black and Devereux, 2011, for surveys), but much less is known about the transmission of wealth from parents to their children and the mechanisms underlying it. ${ }^{1}$ This lacuna is unfortunate for several reasons. First, as is evident from the literature on life-cycle bias (e.g., Haider and Solon, 2006), it is important to find more permanent measures of economic status than what is captured by yearly income measures. In fact, wealth may be a better proxy for long-term economic success than earnings or income as wealth reflects cumulative net incomes. Second, there has been an increased interest in questions related to multigenerational mobility in recent years (Solon, 2015). However, wealth has received very limited attention in this literature. ${ }^{2}$ Third, the importance of inherited wealth for economic inequality has recently attracted much attention in the academic literature (e.g., Piketty, 2011, 2014). One crucial yet largely overlooked aspect is to which extent inheritance also influences the inequality of opportunity in the wealth distribution as measured by the degree of persistence of wealth status across generations.

This paper has two main purposes. First, we estimate the persistence of wealth inequality across several generations. We have access to exceptional wealth data observed at mid-life for individuals in three generations and during childhood/early adulthood for individuals in the fourth generation, which enables us to perform intergenerational wealth mobility estimations across adjacent generations as well as across three and four generations. We build on a growing literature that investigates the importance of multigenerational effects and long-term social mobility using data on outcomes such as income, education and occupation. A prime finding in this literature is that grandparents provide additional information about grandchildren's outcomes, conditional on parent's outcomes, and that long-run social mobility is slow-

\footnotetext{
${ }^{1}$ Among exceptions are Arrondel and Grange (2006), Charles and Hurst (2003), Menchik (1979) and Wahl (2002). There are also a few recent papers by Black et al. (2015), Boserup, Kopczuk and Kreiner (2014), Fagereng, Mogstad and Rønning (2015) and Pfeffer and Killewald (2015). The classical article on the theoretical underpinnings is Becker and Tomes (1979).

${ }^{2}$ There are some recent exceptions: Boserup et al. (2014), using population-wide high-quality administrative data from Denmark and Pfeffer and Killewald (2015), using survey data from PSID, both have access to wealth data for three generations. However, in both these studies, in their main analysis, wealth is measured when grandparents and parents are relatively young: grandchildren (parents) are 37 (35) years of age on average in Pfeffer and Killewald (2015) and 23 (35) on average in Boserup et al. (2014). Given life cycle considerations, this feature of their data sets will likely result in biased estimates of the associations between wealth of grandchildren and grandparents.
} 
er than predicted from an estimate using data on parents and children. ${ }^{3}$ We follow the approach in earlier papers and estimate bivariate regression models of child's wealth on ancestors' wealth, as well as extend the standard first-order autoregressive (AR(1)) parent-child model by also including grandparents', and in some specifications even great grandparents', wealth in the regressions. These estimates constitute an improvement over earlier studies of long-term intergenerational wealth mobility in at least two regards: We are the first to estimate models for three generations measuring wealth of middle-aged individuals. Moreover, we are the first to present any evidence on the transmission of ancestors' wealth to the wealth of great grandchildren (although still young), where we are able to link families across generations through individual identifiers. ${ }^{4}$

Our second contribution is to quantify the importance of transfers to the intergenerational persistence in wealth. Bequests and gifts constitute an obvious channel through which wealth persistence arises across generations, but despite this there are few studies of how large a share of wealth mobility that can be attributed to these transfers. ${ }^{5}$ Using detailed information about inheritances, hand-collected from individual inheritance tax records and thus perfectly matched to both decedents and their heirs, we make two types of estimations. One adds inheritances to the intergenerational wealth model, and the other is based on a constructed "inher-

\footnotetext{
${ }^{3}$ This statement is based on findings from a number of recent papers studying different outcomes and data sets from different countries: In addition to the few references studying wealth listed in footnote 2, some additional studies are Adermon, Lindahl and Palme, 2016, (outcomes: education, earnings and occupation; country: Sweden), Braun and Stuhler, 2014, (education and occupation; Germany) Clark, 2014, (education and occupation; various countries); Lindahl et al. 2015, (education and earnings using the same data set as in this paper), Long and Ferrie, 2013, (occupation; U.S.); Modalsli, 2016, (occupation; Norway), Mollegaard and Jaeger, 2015 (education and "cultural capital"; Denmark) and Olivetti, Paserman and Salisbury, 2016 (earnings; U.S.). For a survey that includes the older literature on multigenerational mobility, see Solon (2015). Recent theoretical contributions by Solon (2014) and Stuhler (2013) discuss reasons for these empirical findings.

${ }^{4}$ As opposed to Clark and Cummins, 2014, who use (rare) surnames to form linkages between multiple generations. They find strong wealth associations between individuals and their (surname linked) ancestors.

${ }^{5}$ There are a few very recent studies touching on this question. Fagereng et al. (2015), studying wealth transmission among 2,265 Korean-born adoptees in Norway, find that the association in wealth between adopted children and their adopting parents are not driven by gifts, inter vivos transfers or inheritances. However, given that the parents are between 64 and 66 years of age, there are likely very few in the child generation that have actually received inheritances. Black et al. (2015), for Sweden (focusing on a sample of Swedish-born adoptees), and Boserup et al. (2016), using population-wide data for Denmark, both lack information on actual inheritances. Instead, they use the timing of death of the parent(s) to infer how the wealth transmission coefficient changes before and after the death of the parent(s). Both studies find a large increase in the wealth rank correlation after the death of parent(s). Pfeffer and Killewald (2015), for the US, find that the parent-child wealth estimate decreases with about 11 per cent when they add inheritances to the AR(1) model of parent's and child's wealth. The inheritances measure used is from a question in the PSID to respondents about large (above $\$ 10,000$ ) inheritances received ( 28 per cent of the sample). Given that parent's age on average is about 72 when inheritances are last measured, it is likely that the majority of children have at least one living parent, and hence that observed inheritances are very incomplete.
} 
itance-free" measure of child wealth that draws on the information about the exact timing of wealth measurement and received inheritances in people's life span. This analysis adheres to the recent literature on the importance of inherited wealth in society for different economic and distributional outcomes. ${ }^{6}$

As our dataset contains measures of lifetime earnings and educational attainment for the first three generations, we are also able to further investigate the importance of human capital for the wealth transmissions across generations.

We are able to generate a number of interesting findings. We find parent-child rank correlations in the range of $0.3-0.4$, which are larger than what has been found for other Scandinavian countries. The parent-child rank correlation has, perhaps surprisingly, increased over time. Further, we find grandparents-grandchild rank correlations of $0.1-0.2$, although there is a quite limited role for grandparents' wealth, conditional on parents' wealth. The parent-child correlation is basically unchanged if we control for grandparents' wealth. Bequests and gifts account for more than 50 per cent of the parent-child wealth correlation while earnings and education together only explain about 25 per cent.

\section{Data and Descriptive Statistics}

\subsection{Data and variables}

The dataset used in this study originates from a survey of all pupils in Malmö (the third largest city in Sweden) conducted when they attended 3rd grade in 1938. The typical child in this "index generation" was born in 1928. Data were also collected for the parents. This included survey information on father's occupation and parental earnings from tax registers for several years. A lot of effort was spent on collecting the parental information resulting in nearcomplete coverage (above 95 per cent). ${ }^{7}$ It should be noted that the study population covers both the city of Malmö with suburbs and its agricultural surroundings, and this sample has

\footnotetext{
${ }^{6} \mathrm{~A}$ number of studies have examined the aggregate macroeconomic importance of inherited wealth (Piketty, 2011, 2014; Piketty and Zucman, 2014, 2015; Ohlsson, Roine, and Waldenström, 2014) whereas other studies study how inheritances affect the cross-sectional wealth distribution (see, e.g., Wolff and Gittleman, 2014 and Elinder, Erixson and Waldenström, 2016, for two recent examples).

${ }^{7}$ The material was originally collected by Siver Hallgren and developed by Torsten Husén. Hallgren (1939) is the first study published using this data set. See also de Wolff and Slijp (1973), Palme and Sandgren (2008) and Lindahl et al. (2015) for further description of the Malmö study data set.
} 
been shown to be very representative of the whole Swedish population at this time. For example, Lindahl et al. (2015) show that the distributions in education and earnings are very similar for descendants of those in the original sample compared to the population of Swedes. If we compare the cross-sectional distribution of wealth in our study population and the total Swedish population, documented by Roine and Waldenström (2009), trends appear to be roughly the same (inequality falls after the 1940s and stabilize from the 1970s onwards) but the level of inequality is clearly higher in Malmö than in the country as a whole.

Information about spouses has been added later, including information about dates of birth and death, earnings histories and educational attainments, all drawn from high-quality administrative registers. The result is a dataset consisting of information on up to four generations of the same families, where the great-grandparents were typically born in the late nineteenth century and the great-grandchildren typically finished their education in the early twenty-first century. Because of the excellent quality of the Swedish registers, it has also been possible to add information for most of the descendants. For example, if they have moved away from Malmö but stayed in Sweden, they are included in the data set. ${ }^{8}$

For the purpose of this study, we have extended the dataset by adding detailed information about personal wealth and inheritances. Our data on wealth are collected from official administrative records. For all generations we observe tax-register wealth and for the two first generations we also observe wealth at death reported in estate inventory reports. Data on taxable wealth, wealth at death and inheritances for the first two generations were collected manually by us from tax registers stored in county archives. Because of the limited coverage of estate wealth for the second generation and inheritances received for the third generation, we do not use this information in the analysis. ${ }^{9}$

The definitions of assets, liabilities and net wealth are in principle the same for all generations and across the wealth tax records and the estate inventory reports. Non-financial assets include housing, urban and agricultural land and to some degree various kinds of valuables (consumer durables, antiquities, art etc.); financial assets include bank deposits and cash,

\footnotetext{
${ }^{8}$ Regarding the issue of mobility, we note that in 1993,38 per cent of the third and fourth generations still lived in Malmö, an additional 31 per cent lived elsewhere in the county where Malmö is situated, 8 per cent lived in the county of Stockholm, and the rest were quite evenly spread out in the rest of Sweden (Lindahl et al., 2015).

${ }^{9}$ The limited coverage is because only about one-third of the parents in the second generation have died at the end of our sample window.
} 
stocks (listed and non-listed), some insurance savings and miscellaneous private claims; liabilities include private loans (mainly mortgages) and student loans from state institutions. Some items are better covered in the estate inventory reports: for assets the net life insurance proceeds and consumer durables, and for liabilities funeral expenses, executor's commission, attorney fees and taxes paid (primarily capital gains taxes).$^{10}$ For the first two generations assets are reported in tax-assessed values which are generally (but not always) lower than current market values. ${ }^{11}$ For more details on the wealth data, we refer to Appendix A.

The first generation's wealth measure is based on observed taxable wealth in 1945 and 1952, which is thus measured around the age of 48 and 55. Some measurement issues warrant specific attention. For both years, wealth is bottom-coded, and especially so for 1952 when we only observe wealth for the wealthiest eight per cent of the population. For 1945 we observe all positive wealth holders, as long as positive wealth is indicated in the tax registers. ${ }^{12}$ Hence, the left censoring for the 1945 measure consists of those with around zero or negative wealth. We observe roughly the top 40 per cent of the families to have positive wealth in 1945 . This implies that for most of the first-generation sample we only use wealth in 1945 . While such small coverage is problematic, it should be noted that the top tenth of the wealth distribution holds a sizeable share of total net wealth; looking at Sweden as a whole, the richest wealth decile held 83 per cent of all wealth in 1945 and 75 per cent in 1951 (Roine and Waldenström, 2009). In our empirical analysis, moreover, we present top decile regressions that circumvent much of the coverage problem. In section 2, we further examine if the different measurement issues of the first-generation wealth variable influence the results. Specifically, we impute wealth for the bottom-censored observations as well as using two alternative wealth measures: "capitalized wealth" from a secondary source, ${ }^{13}$ and "estate wealth" (i.e., wealth at death

\footnotetext{
${ }^{10}$ A public investigation of private wealth in 1967 found when comparing estate inventory reports with the previous year's wealth tax returns of the deceased persons that personal assets (i.e., durables) and debts were much better covered in the estate inventory reports (SOU 1969, p. 276). See Henrekson and Waldenström (2016) for further descriptions of the Swedish inheritance taxation and the structure of estate inventory reports.

${ }^{11}$ Before World War II tax-assessed values were generally aimed at being equal to market values, but in the postwar era they have mostly been set with a discount: real estate was valued at 75 per cent of market value and listed stock values have also been set at lower than market values.

${ }^{12}$ The lowest observed wealth amount is 900 SEK in 1945 (about 15,000 SEK today which is equal to about 1,500 euro) and 2,900 SEK in 1952 (about 40,000 SEK or 4,000 euro).

${ }^{13}$ This alternative wealth measure, "capitalized wealth", divides tax-reported capital earnings (interest and dividend earnings) in 1937 (only men) and 1945 and 1952 (both men and women) by an assumed real rate of return of three per cent and then averages across all three years. Capitalized wealth differs from taxable wealth by disregarding all the assets that do not yield taxable cash returns, notably most types of real estate and land but also some financial assets, but to the extent that ownership of cash-yielding financial assets and total wealth is posi-
} 
which is not bottom coded). Our conclusion from these sensitivity tests is that measurement error is surprisingly low and hence that the estimates where we include first generation wealth are not severely biased.

The second generation's wealth is based on taxable wealth observed in the administrative registers during the years 1985, 1988 and 1991 (thus measured at ages 57-63). ${ }^{14}$ Notable is that wealth in the first two of these years is censored from below at zero whereas this is not the case for 1991, the reason being different reporting routines at the tax authority after the Swedish tax reform of 1990-1991. The third generation's wealth is measured in 1999 and 2006 (thus around ages 42-49) in Statistics Sweden's wealth register, and the fourth generation's wealth is measured in 2006 (around age 20). Unlike the taxable wealth reported on tax returns that we use for the first two generations, the wealth-register data combine property tax data on non-financial assets with third-party (banks and financial intermediaries) reported statements on financial assets and liabilities. Note that the fourth generation is very young compared to the first three generations when we observe wealth and we therefore analyse their intergenerational outcomes separately from the main analysis.

Our preferred wealth measures for these four generations are constructed by averaging tax wealth (in 2010 prices) over the years available for each individual, using only non-missing years. In the estimations we always use the sum of wealth across parents, grandparents, and great grandparents, respectively, ("family wealth" for each ancestor generation) and individual wealth for the child generation.

Estate wealth, or terminal wealth, of the deceased in the first and second generations is observed in estate inventory reports which are filed for all individuals with some wealth holdings. ${ }^{15}$ Since estate inventories are always filed individually while we wish to measure the

tively correlated they can be expected to capture the same structures of intergenerational transmission studied here.

${ }^{14}$ Included in the wealth measure for 1985 and 1988 is the tax value of real estate, which is 75 per cent of market value. Because we also have separate information on real estate tax value, we can scale this up to market value and add the difference to the wealth measure. This reduces the number of zero (censored) observations by around 10 percentage points. Regressions using this alternative definition of wealth produces results similar to our main analysis (see Online Appendix Table 1, Panel A).

${ }^{15}$ These data were collected manually from county archives all over Sweden where the individuals had died until 2001, when the Swedish tax authority took over the responsibility for storing all the country's estate inventory reports. Some of the deceased in our sample do not have estate inventory reports. This is primarily due to the insignificance of their wealth, in which case only a so-called estate notification ("dödsboanmälan") was filed. 
joint parental wealth at death, we need to combine the value of two estates recorded at different points in time. In order to measure the joint parental estate wealth that accounts for the differential times of death and potential inter-spousal transfers from the first deceased parent to the remaining parent, we follow previous wealth mobility literature using estate wealth data (see Menchik, 1979; Wahl, 2002) and construct a specific measure, the peak midparent wealth, which is equal to $1 / 2 \cdot\left(w_{\text {First deceased }}+\max \left(w_{\text {Second deceased }}, 0\right)\right)$.

Inheritances are the value of bequests from parents at death to their children in the second generations. ${ }^{16}$ The inheritance lot of each heir was calculated and reported by the tax authorities in inheritance tax records ("arvsskattestegar"), which were then attached to each deceased individual's estate inventory report. Because of the tax purpose, these inheritance lots were based on a close scrutiny of the probated wealth, accounting for wills if they existed and accounting for taxable inter vivos gifts made within ten years of the testator's death. Note that because of this source of inheritance information, we can observe exactly when inheritances were received. Combined with the fact that we observe this information for a very large fraction of the sample, our study makes a unique contribution to the understanding of how inheritances influence the intergenerational transmission of wealth.

Finally, we also have access to data on education for all four generations and earnings histories for the first three generations. We derive measures of years of schooling and log lifetime earnings in a similar way as in Lindahl et al. (2015). ${ }^{17}$ Just like for wealth, residualised earnings and years of schooling are averaged across ancestors for grandparents and for great grandparents. For more details on the education and earnings data, we refer to Appendix B.

\subsection{Sample restrictions and descriptive statistics}

Our dataset is based on 1,542 individuals in the "index generation", which is the original population studied in the 1930s and the second generation in our multi-generational panel. Of these, 1,491 have at least one parent present in the data. Wealth is observed for at least one

\footnotetext{
${ }^{16}$ We do not include inheritances from others than the parents, i.e., siblings, other relatives or non-relatives. But as Elinder, Erixson and Waldenström (2016) show for Sweden and Wolff and Gittleman (2014) show for the U.S., that almost two thirds of inheritances received come from parents.

${ }^{17}$ A few differences are that we, to improve comparability with our wealth measures, use family earnings instead of father's earnings and that we use average years of schooling for parents. We also note that i) for the first generation, the education measure is only available for the fathers and is derived from information on occupation, and ii) earnings in the first generation is for 4 out of 5 years only available as the sum of labor earnings and capital earnings.
} 
parent for 1,291 individuals in the index generation, and own wealth for 1,356 individuals. For 1,147 of these we observe both own and parental wealth, and this is our main analysis sample for the index generation. For the third and fourth generations we use as many observations as we can, given that they are descendants of these 1,147 individuals and that they are observed in the wealth registers (true for almost all individuals). This results in 2,100 individuals and 3,755 individuals, respectively, in the third and fourth generation. ${ }^{18}$ The sample for which we have access to estate wealth is slightly smaller (1,093 individuals in the first generation), and we observe inheritances given from the first generation for 809 individuals. These are the samples for which we show descriptive statistics in Tables 1a and $1 \mathrm{~b} .{ }^{19}$

[Tables $1 \mathrm{a}$ and $1 \mathrm{~b}$ about here]

Table 1a reports descriptive statistics for our wealth variables for the individuals used in the estimations in this study. We present statistics for wealth for all four generations, estate wealth for generation one and two, and inheritances for generation two, in addition to the other variables used in the estimations. We show means and standard deviations (the first column) as well as various percentiles. All wealth and earnings measures are presented in thousands of SEK in 2010 prices ( 1 USD $=6.85$ SEK in December 2010). Since we always use family wealth for ancestors' and individuals' wealth for descendants in our regressions, we show summary statistics separately for the second, third and fourth generation samples.

Looking first at the main wealth measures, we see that mean wealth more than doubled between the first and second generations (from 182 to 446 thousand SEK), but grew at an even higher rate between the second and third generations (from 446 to 1,609 thousand SEK). This is partly explained by the switch from using tax-assessed values to market values. Because we measure the wealth of the fourth generation at a much younger age (19 on average) than for the earlier generations, they have an average wealth of only 103 thousand SEK, which should be compared to the individual wealth levels for the second generation (255 thousand SEK) and the third generation (705 thousand SEK). It is also worth noting that wealth is more evenly distributed among the later generations compared to the first, where most people have zero

\footnotetext{
${ }^{18}$ If we lessen this descendant requirement, meaning that we do not require that we observe wealth for grandparents, we can observe wealth for 2,579 individuals in the third generation and wealth for 4,592 individuals in the fourth generation. The estimated intergenerational rank-rank correlations are very similar for this larger sample.

${ }^{19}$ Summary statistics for the corresponding percentile ranked variables, which we use in the actual estimations, are shown in the Online Appendix Table 2.
} 
wealth, so that the mean is driven by a smaller subset of relatively wealthy individuals. In subsequent generations a majority of individuals have positive wealth. ${ }^{20}$ Wealth inequality appears fairly stable between the second and third generations, but is much higher in the younger fourth generation. ${ }^{21}$ Unlike taxable wealth, the estate wealth is not left-censored. Estate wealth is positive for most of the individuals in the first generation (only 10 per cent has zero or negative values). Inheritances are substantial in relation to own wealth, which represents a first indication that this is likely to be an important channel for intergenerational wealth correlations.

Table $1 \mathrm{~b}$ presents means and standard deviations for (residualised) earnings for the first three generations, year of death for the first two generations, and educational attainment and year of birth for all four generations. In the first generation, almost everyone has died, with an average age at death of 75.2. For the first generation, because wealth data is missing for many women, only around a third of the sample is female. ${ }^{22}$ Subsequent generations are virtually balanced on gender, since we observe wealth for almost everyone in these generations. Note that earnings and schooling are missing for a few individuals for which we have wealth observations.

\section{Wealth transmission across two, three and four generations}

\subsection{Graphical evidence and measurement issues}

We start the empirical analysis by showing graphical evidence for the wealth relationship across the distribution. Figure 1 displays kernel regressions of children's wealth rank on their ancestors' wealth rank. ${ }^{23}$ In each graph, the solid line shows the kernel regression estimate,

\footnotetext{
${ }^{20}$ For the second, third and fourth generations, there are people with negative net wealth whereas no cases with negative net wealth are reported for the first generation for tax-administrative reasons, as we mentioned above. To make sure that this censoring of the first-generation wealth does not affect our findings we run sensitivity checks where we homogenize the wealth variables by censoring all of them from below at zero (see Online Appendix Table 1, Panel B).

${ }^{21}$ Using the individual level data, the P90/P50 ratios are 5.52 and 5.72, respectively, for the second and third generations and 18.6 for the fourth generation. Note that because two of the three years used to calculate wealth for the second generation are censored from below at zero, it is hard to compare the full distributions between generations.

${ }^{22}$ This is still an advantage compared to Lindahl et al. (2015) where we only observed earnings for fathers in the first generation and for men in subsequent generations.

${ }^{23}$ Chetty et al. (2014) show figures plotting average child rank on the y-axis against parental wealth percentile. That approach corresponds to estimating a local constant kernel regression using a rectangular kernel and a bandwidth of 1. Our approach uses a more efficient local linear kernel regression with an Epanechnikov kernel,
} 
grey lines along the bottom are rug plots showing the density of the data while the dashed line indicates the best linear fit from a bivariate regression (to be discussed further below).

[Figure 1 about here]

The association between parent and child wealth is quite well approximated by a linear specification, with the kernel almost tangent over most of the support in the parental wealth distribution. In the tails, however, there are deviations; in all parent-child graphs ( $a, b$ and d) there is an increase in the slope around the parental top decile group and in panels $b$ and $d$ there seems to be a flat slope over the bottom decile group. Looking at the role of grandparent wealth in panels $\mathrm{c}$ and $\mathrm{e}$, the overall correlation is, as expected, smaller but otherwise very similar to that of parental wealth showing a largely linear association that becomes steeper at the top. Finally, panel f shows the regression of the fourth generation on their great grandparents. Here, the overall correlation is very flat but once again has a steeper slope in the top. ${ }^{24}$ The linear intergenerational association in wealth with stronger transmission in the top decile and sometimes lower in the bottom deciles is similar to findings in previous studies, in particular the results for Denmark by Boserup et al. (2014) and for Sweden by Black et al. (2015).

We proceed to present two types of main estimations. The first is rank-rank correlations (the slope of the lines shown in the figures), which has the advantages of allowing for observations with zero wealth and to be less sensitive to outliers, and which have been used in several recent papers on intergenerational income and wealth transmission (e.g., Chetty et al., 2014; Boserup et al., 2014). Because of the non-linearity at the top of the distribution, and the bottom censoring for first generation wealth, we also present results from a second model, top decile regressions, in which we transform wealth into a binary variable taking the value one for the top 10 per cent of the wealth holders in each generation. We choose top decile ${ }^{25}$ because this is where we, approximately, observe a steeper slope (see Figure 1) and because we

which is specifically important given our smaller sample size. Note also that the variables have been residualised by regressing out birth cohort group dummies for both generations (see section 2.2), and the residuals have been rescaled to have the same range as the original percentile ranked variables.

${ }^{24}$ It should be noted that because of the large number of observations with zero wealth in the first generation (see table 1a), there is a mass point close to the bottom of the distribution and relatively large confidence intervals in this domain. This results in a set of spikes in the rank assigned, where the spikes will be determined by the fraction of zeros (within birth cohort groups). This is why the lines stop at around the 25th percentile in figures 1a, $1 \mathrm{c}$ and $1 \mathrm{f}$. This calls for some caution in interpreting the patterns in the left part of the figures.

${ }^{25}$ Results are qualitatively similar if instead we use an indicator for the top 15 per cent or for the top five per cent - see Online Appendix Table 3. 
have the advantage of having continuous wealth measures from two separate years at the top of the wealth distribution for the first generation (hence minimizing measurement error concerns when assigning observations to the top decile of the wealth distribution).

An advantage with the rank-rank and top decile regressions, compared to many alternative transformations, is that mismeasurement of the zero wealth observations does not matter as long as they are ranked correctly. This is important since about 61 per cent of the observations in the first generation have no wealth reported. If we instead use log wealth, we throw away over 60 per cent of the families in the first generation (and about 18 per cent in the second generation) and would is in effect estimate intergenerational associations for only about onethird of the sample, all located in top of the wealth distribution. If we, in order to increase the sample for which we can use logs, recode those with zero wealth to having some small wealth, our regression estimates are extremely sensitive to small variations in that wealth amount. An alternative that is sometimes used instead of logs is the inverse hyperbolic sine (IHS) transformation, which can be used in the presence of zero and negative observations (Pence, 2006). Unfortunately, the IHS transformation turns out to be sensitive to very small deviations from zero, and is thus not suitable in the presence of bottom censoring. We therefore settle for estimating rank-rank correlations and top decile regressions in our main estimations. In a complementary analysis we show results using alternative wealth measures for the first generation: capitalised wealth, estate wealth (which is not censored) and a wealth measure where we have imputed the bottom coded observations using information on education and total earnings (including capital income).

\subsection{Regression results for the first three generations}

Our baseline regression estimations are based on the following linear equation:

$$
w_{i t}=\alpha_{0}+\alpha_{1} w_{i t-1}+\alpha_{2} w_{i t-2}+e_{i t},
$$

where $w_{i t}$ is wealth of child $i$ and $w_{i t-j}$ is wealth of the parents $(j=1)$ and the grandparents $(j=2)$. We use individual wealth for the child generation and family wealth for the parent and grandparent generations. In our main regressions we use wealth measures scaled in percentile ranks, grouped by birth year, which means that the estimates can be interpreted as rank 
correlations. ${ }^{26}$ All regressions include corresponding birth cohort group dummies. As mentioned above, we also estimate equation (1) as a linear probability model using indicators for belonging to the top wealth decile as dependent and explanatory variables. A coefficient from this regression measures the conditional probability of being in the top wealth decile given that your parents or grandparents were in the top wealth decile. Under perfect mobility, this probability would be 10 per cent.

Table 2 presents the baseline results. Beginning with Panel A, columns 1 and 2 show twogenerational rank correlations (with $\alpha_{2}=0$ in equation 1). A primary result is that there is a relatively strong wealth correlation: 0.30 between first and second generations and 0.39 between second and third generations. A second finding is that the wealth rank correlation appears to have increased over time and the difference is statistically significant. Columns 3 and 4 show three-generational rank correlations. Column 3 presents the rank correlation between the wealth of children and their grandparents $\left(\alpha_{1}=0\right)$. The estimate is 0.17 and highly significant, which amounts to about 40 per cent of the rank-rank correlation for parents and children in column 2. ${ }^{27}$ Column 4 shows results from estimation of AR(2) regressions. Parents' wealth is basically unaffected by including grandparent wealth and grandparent wealth has a positive (0.04) but imprecisely estimated effect on a person's wealth status $(t=1.37)$.

Panel B's top decile regressions typically show smaller correlations than in Panel A, but the overall pattern is the same. ${ }^{28}$ This is an early indication that the bottom-censoring of the first generation's wealth is not worrisome (we discuss this issue further below). Persistence in the top is quite small in the second generation, with an estimate of 0.18 , but relatively high in the third generation with an estimate of 0.34 which is more than three times higher than under perfect mobility. Estimating the relationship between children and grandparents we find that

\footnotetext{
${ }^{26}$ Because of our limited sample size, it is not feasible to rank by birth cohort. Instead, we group birth cohorts so that each group has at least around 100 observations. While most such groups cover at most two or three cohorts, some groups in the tails span more cohorts (because the index generation is born in or around 1928, birth years follow a single-peaked distribution in our data set). To check if this affects results, we have tried dropping these tail groups entirely from the analysis, and results are mostly unchanged. We have also tried increasing group size to contain around 200 observations, and again results are mostly unchanged.

${ }^{27}$ It should be noted that in the main regressions (in this paper and also for earnings in Lindahl et al., 2015) not all observations represent unbroken family lines. For example, it could be that we observe wealth for a person's father and maternal grandfather, but not for their paternal grandfather. When we restrict the sample to only unbroken family lines, the grandparent-grandchild correlation is 0.136 (see Online Appendix Table 4).

${ }^{28}$ To say that they are smaller is a bit misleading, since the range from perfect mobility to perfect immobility is smaller for the top decile regression compared to the OLS regressions: in the top decile regressions, 0.10 is perfect mobility and 1.00 is perfect immobility, which should be compared to 0.00 and 1.00 in the OLS regressions.
} 
the persistence at the top is 15 per cent, which amounts to 45 per cent of the persistence between these children and their parents (column 2). When we estimate the most general version of equation (1), we again see that parents' wealth is, again, basically unaffected by including grandparents' wealth. However, grandparents' wealth has a positive estimated effect on a person's wealth status, which is now a bit more precisely estimated $(t=1.79) .{ }^{29}$ Hence, we conclude that grandparents' wealth matters at the top of the distribution, even when we control for parents' wealth.

[Table 2 about here]

\subsubsection{Does measurement error in the first generation's wealth matter?}

The first generation's wealth in 1945 and 1952 are bottom-coded as described above. When correlating wealth across these two years, the "raw" wealth including all the zeroes has a correlation of approximately 0.30 whereas only using the top group observed in 1952 (and in most cases also in 1945) the correlation is high, well above 0.9. In other words, wealth seems to be measured consistently over time and using both these years should therefore decrease the measurement error in the top decile measure significantly, which means that our top decile regression estimates are unlikely to be biased by measurement error.

The impact of measurement error due to the bottom coding could be more important, especially for the rank-rank correlations reported in columns 1, 2 and 4 of Table 3, Panel A. We test this in two ways.

[Table 3 about here]

\footnotetext{
${ }^{29}$ As expected from the figures and the estimates shown in Table 2, there are some non-linearities present that result in larger estimates at the top of the distribution. We show elasticities and rank correlations estimates in Online Appendix Table 5 (panels D and E) for the sample with positive wealth amounts (about one third of the three generation sample), where we find that child-grandparent wealth estimates (whether or not we are controlling for parents' wealth) are larger than the rank correlations for the full sample in panel A of Table 2, but more in line with the top decile regression in Panel B. Interestingly, the elasticities and rank correlations, for the smaller sample with positive wealth, are similar regardless of whether we estimate elasticities or rank correlations. Hence, it is the selected sample, not whether we use ranks or logs, that explain these results. In Panels A-C we also show the sensitivity of the results when we us the IHS transformed wealth variables - even very small variations in the bottom coded values (making minor adjustments to everyone in the first generation with exactly zero wealth, by giving tiny amounts (10 or 1000 Swedish kronors, equivalent to 1 or 100 Euros, respectively)), can have enormous effects on the estimates.
} 
First, we rerun the main specification from Table 2 but instead use four alternative measures of first-generation wealth: 1) "capitalized wealth", which is average taxed capital income in 1937, 1945 and 1952 divided by a real rate of return, 2) "estate wealth" covering the whole distribution of wealth, but measured at the end of life for individuals in the first generation, ${ }^{30}$ 3) "imputed wealth", which contains values for the many bottom-coded observations in our main measure imputed using family total earnings (including capital income) and years of schooling. ${ }^{31}$ The results in Table 3 show that all these alternative measures generate results very similar to the baseline findings above. ${ }^{32}$ Transmission of parental wealth is large and significant for both the second and third generations, though clearly higher in the latter case underlining the possibility of a downward time trend in wealth mobility. Grandparental wealth is significantly positive when included on its own, but statistically insignificant when parental wealth is also included. The notably smaller grandparental estimate in Panel B's column 4 is likely due to the fact that estate wealth is highly correlated with inheritance which is typically not transferred to grandchildren. ${ }^{33}$ We show kernel regressions of children's wealth rank on their parents' and grandparents' rank for the various measures (corresponding to Figure 1) in Online Appendix Figure 1.

The second test is to impose bottom-censoring on second generation wealth at the same place (around the 60th percentile) as for first generation wealth, and re-estimate the rank-rank wealth correlation between the third and second generation, using censored second generation wealth measure. The resulting estimate increases to 0.44 , which thus suggests that the increase over time is even more pronounced. If we then impute the second generation wealth measure, and use that measure in the estimations, the estimate becomes 0.39 , which is very close to the actual estimate in column 2 of table $2 .{ }^{34}$ Hence, imputation works extremely well, which gives a lot of credibility to our estimates involving first generation wealth in Panel C of Table 3.

\footnotetext{
${ }^{30}$ The rank correlation between "capitalized wealth" and "estate wealth" is 0.48 and the rank correlation with the main wealth measure is 0.60 for capitalized wealth and 0.52 for estate wealth. Hence, all these measures, although clearly related, contain a lot of independent information.

${ }^{31}$ Imputation is based on estimating a Tobit regression and predicting wealth ranks for the censored observations. We perform bootstrap imputation with 1000 draws to account for the uncertainty in the prediction step. Correlations with the main wealth measure is 0.35 for earnings and 0.20 for years of schooling.

${ }^{32}$ We decided not to use one of the measures as instrument for another, because two of the measures capture different aspects of wealth (the capitalized and estate wealth measures) and because the imputed measure is partly determined by education and earnings which are unlikely to be excludable in the second stage.

${ }^{33}$ If we impute the bottom coded wealth observations with the rank based on estate wealth we obtain very similar results as reported in Panel A of table 2 (see Online Appendix Table 1, Panel C).

${ }^{34}$ See Online Appendix Table 6.
} 
Based on these additional results we conclude that measurement error in the first generation wealth measure does not alter the conclusions from our main regressions.

\subsubsection{Summarizing the findings from the three generation regressions}

Let us briefly summarize the central results from the three-generation regressions and relate them to findings in the literature. There is a relatively strong wealth correlation: it is 0.30 between the first and second generations and 0.39 between the second and third generations. The latter estimate can be compared to recent estimates of rank correlations in wealth for Scandinavian countries and the U.S.: It is clearly larger than the ones reported for Denmark in Boserup et al. (2014) and for Norway in Fagereng et al. (2015), slightly larger than the one reported for Sweden in Black et al. (2015), and very similar to the estimate reported in Pfeffer and Killewald (2015) using U.S. survey data from the PSID. An earlier well known study by Charles and Hurst (2003) also used PSID data and found a similar sized wealth elasticity of about 0.36 . Because of bottom coding of first generation wealth, we are not able to credibly estimate wealth elasticities connecting the second and first generation. However, the wealth elasticity between the third and second generation is 0.32 in our data $(n=1,609$ or about 75 per cent of the total sample), so only somewhat lower than our wealth rank correlation of $0.39 .^{35}$

The wealth rank correlation has increased over time and the difference is statistically significant. This is a somewhat surprising finding given that Lindahl et al. (2015), using the same data set as in this paper, did not find this to be the case for schooling and earnings. ${ }^{36}$ The mechanisms for wealth transmission may be different from those for schooling and earnings, and the importance of these various mechanisms can also have evolved differently over time. As we show below (section 5) the importance of schooling and earnings in explaining wealth transmission across generations has not changed over time. Although we rule out measurement issues related to bottom coding in the previous subsection as an explanation for this trend, it should still be remembered that the wealth measures are not exactly comparable

\footnotetext{
${ }^{35}$ The difference compared to our rank correlation appears to be driven entirely by sample selection as the rank wealth correlation is 0.29 using this sample of $n=1,609$.

${ }^{36}$ When we compare results with Lindahl et al. (2015) we always use the standardized coefficient estimates (Mean $=0 ; \mathrm{SD}=1)$ reported in that paper.
} 
across generations (se section 1.1) and that the sampling of the data set is such that comparisons of intergenerational estimates over time is not straightforward. ${ }^{37}$

Another central finding is that grandparents' wealth has a positive but imprecisely estimated effect on a person's wealth status, conditional on parental wealth. Both Boserup et al. (2014) for Denmark and Pfeffer and Killewald (2015) for the U.S. are also able to estimate AR(2) models for wealth and find quite large grandparental wealth effects, conditional on parents' wealth. The conditional grandparental estimate is 72 per cent of the unconditional estimate in Boserup et al. and 49 per cent in Pfeffer and Killewald, whereas in our study it is 25 per cent (the OLS estimates reported in Panel A of Table 2) or 40 per cent (the top decile regressions in Panel B). However, the parents and children are quite young in both these studies, which indicate a larger role for grandparents because grandparents are more important in the younger life of parents and grandchildren and because measuring wealth of parents in their $30 \mathrm{~s}$ will not accurately measure their mid-life wealth. As the grandparents are relatively older (47 in Boserup et al. and 62 in Pfeffer and Killewald) wealth for them are measured more correctly and will therefore capture some of that missed variation. The importance of grandparents' wealth will thus be overestimated and that of parent's wealth will be underestimated. However, we note that a $95 \%$ C.I. around our main estimate for grandparental wealth do cover the main estimate in Pfeffer and Killewald and also cover an estimate in Boserup et al. when they instead use an older sample. ${ }^{38}$ How do these results match those reported in Lindahl et al (2015), where the AR(1) model was rejected for schooling and (marginally) for earnings? As it turns out, our results for wealth are not statistically different from those for earnings, partly due to the poor precision of the estimated coefficients for grandparents in the AR(2)-model for both these outcomes. ${ }^{39}$

\footnotetext{
${ }^{37}$ As explained in section 1, the data set is based on the population of 6th graders attending schools in Malmö in 1938. This second generation (and their parents) is therefore representative of the population of 6th graders in Malmö at that time. However, the third generation are descendants of these individuals, and hence not necessarily representative of the population of 6th graders in Malmö at that later time (they can for instance have relocated to other parts of Sweden whereas immigrating families to Malmö is not represented).

${ }^{38}$ The conditional grandparental coefficient estimate decreases slightly (by 22 percent) in an AR(2) regression in Boserup et al. (2014) when they instead use an older sample (but that suffers from potential selection issues).

${ }^{39}$ To estimate the grandparental wealth association in the AR(2)-model precisely enough to draw strong conclusions clearly requires more data. Note that Lindahl et al. (2015), in their AR(2) regressions, found standardized conditional grandparent estimates [95 per cent C.I.] of 0.110 [0.054, 0.166] for years of schooling and 0.064 [$0.004,0.132]$ for earnings, whereas for wealth we find $0.041[-0.019,0.101]$ using the same generations. Hence, trivial effects can be ruled out only for schooling, and large effects can't be ruled out for any of the outcomes.
} 
Clark (2012) and Clark and Cummins (2014) propose a simple model of the evolvement of wealth over time, where the parameter "long-run intergenerational persistence in social status" is estimable using data on at least three generations (see Appendix C). If we calculate this parameter using the data in this paper, we get an estimate equal to 0.48 for wealth, which should be compared to 0.49 for earnings and 0.71 for schooling using the estimates in Lindahl et al. (2015). Comparing these long-run estimates to the bivariate estimates using data on two generations, we conclude that long-run intergenerational mobility is somewhat overstated using data on only two generations for wealth. ${ }^{40}$

Lastly, and as a consequence of the prior reasoning, the parent-child wealth rank correlation is unaffected if we control for grandparents' wealth. Hence, even though grandparents' wealth is quite predictive of grandchild's wealth, we must conclude that most of this link appears to be mediated by parent's wealth. We note that, similar to wealth in this study, Lindahl et al. (2015) also found that the parent-child estimates were not much affected by controlling for grandparents' outcomes (the estimate was somewhat lower for schooling but very similar for earnings). This is also a rationale for why we focus on the parent-child estimates when we later turn to investigating mechanisms.

\subsection{Wealth persistence across four generations}

The long-run reach of our dataset allows us to estimate wealth regression models using individuals from four consecutive generations, which appears to be a unique contribution to the literature. The fourth generation in our dataset is made up of children, adolescents or young adults, making this a sample of individuals who themselves have had no, or very little, time to acquire wealth. Hence, as mechanisms differ, compared to intergenerational associations using mid-life wealth for all generations, we should be careful in comparing the results here with those in the previous sections.

Table 4 presents the results of the four-generation regressions. The parental wealth-rank correlation in column 1 of Panel $\mathrm{A}$ is high, about 0.39 , which is very similar to estimates for the third and second generations. However, columns 2 and 3 indicate a fairly strong direct association with grandparental and great grandparental wealth. In the case of grandparental wealth,

\footnotetext{
${ }^{40}$ The average of the 2 generation wealth estimates in panel B of Table 2 is 0.34 , whereas they are 0.32 for schooling and 0.29 for earnings using the estimates reported in Lindahl et al. (2015).
} 
this association holds even when conditioning on the wealth of parents, a pattern that was not as clear for generations $1-3$ in Table 2 .

[Table 4 about here]

Splitting the fourth generation into samples below (Panel B) and above age 18 (Panel C), we see that the multigenerational associations appear to be driven by very young children. Since most of them have not been able to accumulate their own wealth and only very few have received inheritances, we interpret these high associations as primarily driven by various kinds of inter vivos gifts from parents and grandparents (or other relatives). As can be seen in column 1 of Panel B, the wealth of the fourth generation children is very highly correlated with those of their parents and grandparents, very much in line with this reasoning.

So how do the estimates in Panel $\mathrm{C}$ of Table 4 compare with estimates for the threegeneration sample underlying the estimates in Table 2, if we use wealth observed at a younger age for those children? As can be seen in an Online Appendix Table 7, estimates are quite similar to the ones reported in panel $\mathrm{C}$ of Table 4 for the four generation sample. Hence, we conclude that the difference in the results for the three and four generation sample is driven by the differences in age of the child generation. It is probably the case that the younger the children, the larger is the role of grandparents, perhaps because they are able to take a more active part in their grandchildren's life when they themselves are younger.

Also, as argued in Boserup et al. (2016), the parent-child wealth relationship is U-shaped across the life cycle, with largest persistence when the child generation is young (driven by inter vivos gifts and transfers) and old (when they have accumulated capital). They find empirical support for this in Denmark, as we do for Sweden.

\section{The role of inheritance for intergenerational wealth transmission}

Having established a positive association between mid-life wealth of parents and children, and a limited role for grandparents, we now turn to an investigation of mechanisms. In this section we look at the role of inheritance, and in the next section on the role of human capital and labour market productivity, in explaining the transmission of inequality in wealth between parents and children. 
Material inheritance represents a central possible determinant of the intergenerational wealth associations reported in previous sections. As we observe both midlife wealth of the first two generations, terminal wealth of the first generation as well as the exact bequeathed amounts as reported in inheritance tax records, we can actually calculate the present value of inheritances as well as identify their impact on wealth mobility with high precision. To our knowledge this constitutes a unique contribution to the intergenerational mobility literature.

We perform several tests of how important bequests are in the wealth mobility process. To make these tests cleaner, we now measure wealth in the child generation in 1991 (the latest possible year), and restrict the sample to those having received inheritances before that year (so that at least one parent has died before 1991). We also perform tests on a smaller sample where both parents have died.

First, we rerun our baseline regressions but add inheritances, ranked within year of death groups. ${ }^{41}$ Such a "mediating-variable" approach is coarse but potentially captures the role of bequests for the transmission of wealth between parents and children (see Appendix D). The results in Table 5 are shown for the full sample, where bequests come from one or both parents, and for the subsample where we observe inheritances from both parents.

The results suggest that bequests are an important source of an individual's wealth status. Regressing child wealth rank on inheritance rank (columns 1 and 4) show high and statistically significant correlations between 0.32 and 0.38 . Turning to the baseline generational equation (columns 2 and 5), parental wealth correlations are around the same levels as seen before, between 0.26 and 0.31 . When adding ranked inheritance to the baseline model (columns 3 and 6), parental wealth correlations drop to 0.12 and 0.14 , which represents a drop of between 50 and 60 per cent. This is a remarkably large reduction, suggesting that inherited wealth accounts for the majority of the measured intergenerational wealth correlation. We have also

\footnotetext{
${ }^{41}$ We rank within year of death groups rather than birth cohort groups because we want to capture the relative size of the received inheritance at a certain time. Ranking within birth cohorts could be very misleading if parents die at very different times. Ideally we would have ranked within interacted birth cohort-year of death groups, but our data set is much too small for this to be feasible.
} 
experimented with controlling for second and third degree fractional polynomials ${ }^{42}$ in inheritances, leading to a somewhat smaller child-parent wealth estimate (see Online Appendix Table 8).

[Insert Table 5 about here]

One potential problem with comparing the wealth and inheritance estimates in columns 3 and 6 of Table 5 is that a higher degree of measurement error in wealth, relative to inheritance, would lead to worse attenuation bias for wealth, and hence that we would overestimate the importance of inheritance for the intergenerational transmission of wealth. To check this, we rerun the regressions imposing bottom-censoring of inheritance at the same place in the distribution as for first generation wealth. Results are very similar (see Online Appendix Table 9, Panel A), and the drop in elasticity is again such that over 50 per cent are due to inheritances. We also do this analysis for top decile regressions (see Online Appendix Table 9, Panel B), where both wealth and inheritances equal one for the top decile of observations. We find once again a large impact of controlling for inheritances, with a decrease in the child-parent top decile wealth estimate of more than 50 percent.

A second test of the role of inheritance for wealth mobility is to purge children's wealth of the value of inheritance. Suppose that we would have information on inheritances just before measuring wealth in the child generation. This would have allowed us to simply subtract inheritances from wealth in the child generation, and then given us the intergenerational rank correlation in wealth, net of inheritances, without having to estimate the coefficient for the mediating variable inheritances. ${ }^{43}$ With our data on the timing of inheritances in relation to when we measure wealth for the second generation, we can do this analysis indirectly.

\footnotetext{
${ }^{42}$ See Royston and Altman (1994) for a discussion of the method. An advantage with this is that since we include inheritances in levels and control for them semi-parametrically, we sidestep the issue of choosing how to rank inheritances, and are able to directly control for both birth cohort and year of death in a flexible manner.

${ }^{43}$ Since inheritance is a mediating variable in the estimations where we control for parents' wealth rank, it can result in downward biased estimates for parents' wealth (unless the size of inheritances is exogenously determined). This is because the size of the inheritance is likely to be correlated with other mediating variables. If this is the case, adding inheritance as a control variable will also remove some of the correlation running through these other channels.
} 
Specifically, we construct an "inheritance-free" measure of wealth of the child generation which is regressed on the wealth of parents. To do this, specify the following regression model:

$$
w_{i y}=a_{0}+c_{1} I_{i y-t}+\delta\left(t \cdot I_{i y-t}\right)+\lambda\left(t \cdot I_{i y-t}^{2}\right)+\gamma w_{i}^{p}+u_{i y},
$$

where $w_{i y}$ is wealth of the child measured at the end of year $y$ (here 1991), $w_{i}^{p}$ is (mid-life) wealth of the parent and $I_{i y-t}$ is the sum of the child's inheritance received on average at year $y-t$, which is also interacted with a second-order polynomial in average time since receiving the inheritances. The second order polynomial is included in order to allow for a fairly unrestricted growth path of the value of inheritances from $y-t$ to $y$. We include parent's wealth as a control variable since growth rates of inheritances might vary for children with different parental mid-life wealth. Note that both wealth and inheritances in equation (2) are measured in levels.

We construct the "inheritance-free" measure of wealth as follows. After having estimated equation (2) (the first stage), we set the coefficient estimates on the inheritance terms equal to zero and construct the "inheritance-free" measure of wealth as $w_{i y}^{\prime}=\hat{a}_{0}+\hat{\gamma} w_{i}^{p}+\hat{u}_{i y}$, where $y=1991$, for the individuals in the child generation. ${ }^{44}$ Hence, the coefficient estimates and the residuals are estimated from a regression with controls for inheritances. There are few restrictions on the value growth of past inheritances; we simply remove the average size of past inheritances (in constant prices) across time for all heirs. ${ }^{45}$ This "purged" wealth is then ranked within age groups and regressed on parental wealth rank, as in equation 1 (the second stage).

\footnotetext{
${ }^{44}$ Of course, it would be equivalent to calculate $w_{i y}^{\prime}$ as the difference between $w_{i y}$ and the inheritance terms in equation (2).

${ }^{45}$ We have tried alternative approaches, either to do as Modigliani (1988) suggested and assume that past inheritances only grow along with the general price level (which generates lower inheritance values than the ones we use in our preferred estimation of equation 3) or to follow Kotlikoff and Summers (1981) and assume that inheritances grow at the same rate as the whole economy (which generates larger inheritance values). In the Online Appendix Table 10 we try these two variants, and parent-child wealth rank correlations lie between 0.03 and 0.04 in the inflation-adjustment case and between -0.06 and -0.09 when adjusting for GDP growth. These estimates are always statistically insignificant. In other words, these other ways to calculate the present value of past inheritances produce qualitatively similar results as our main inheritance analysis.
} 
Results from these inheritance-purged wealth regressions are presented in Table 6, with Panels A and B reporting first- and second-stage results. Columns 1-3 show the analysis on the full sample, columns 4-6 only consider cases where we observe both parents' bequests to their offspring and columns 7-8 again uses the full sample but constrain inheritances to be fully passed on to children (i.e., setting $c_{1}=1$ in equation 3 ). ${ }^{46}$ Overall, the findings confirm the results above that suggested a large importance of inheritance in wealth mobility and the results are strikingly consistent across specifications. First-stage inheritance effects are large and significant, with main effects being in the range of 2.4-3.0 which is notably larger than 1 . The direct effect falls over time, however, indicating that past bequests matter less for current wealth the farther back in time they were received. Looking at the main results in the second stage, parental wealth effects fall from the baseline of $0.26-0.31$ down to $0.03-0.08$ when removing inheritances. This represents a reduction by between 70 and 90 per cent, which is even larger than the reduction in wealth rank correlations found above. In Online Appendix Figure 2, we show kernel regressions of this purged wealth measure on parents' wealth and how it relates to a kernel regression of child's on parent's wealth.

\section{[Insert Table 6 about here]}

Taken at face value, these results imply that the major part of the intergenerational correlation in wealth runs through the inheritance channel. But if individuals anticipate the size of their future inheritance, they might adjust their savings behaviour so that a person expecting a large inheritance saves less than an individual expecting a small or no inheritance. This would bias our estimates of the correlation net of inheritance downwards, leading us to overestimate the relative importance of the inheritance channel. As discussed in Appendix D, an overestimate of the importance of the inheritance channel would also follow in the mediating-variable approach in the presence of any unobserved mediating variable that is (positively) correlated with children's wealth and with inheritances. However, even if our estimates are lower bounds on the intergenerational wealth correlation absent inheritances, it is noteworthy that they are qualitatively fairly similar despite using two different methods. We therefore conclude that inheritance is an important mediating channel for the intergenerational correlation in wealth. Interestingly, this significant role of inherited wealth seems to be in line with the

\footnotetext{
${ }^{46}$ If we were able to observe child wealth right after the inheritance was given, we would expect $c_{1}=1$ since the time trend terms would be zero and we could then simply subtract the inheritance from child wealth.
} 
findings of Ohlsson et al. (2014) concerning the importance of inherited wealth in the economy as a whole: in the post-war era they find that about half of total private wealth in the economy is inherited, a result that is similar to that found for France by Piketty (2011).

\section{The role of other factors: human capital and labour productivity}

In addition to material transfers, the intergenerational transmission of wealth may also work through human capital and labour market productivity channels, as suggested by the theoretical models of, e.g., Becker (1974) and Becker and Tomes (1979). Our dataset includes measures of educational attainment and lifetime earnings for the first three generations, allowing us to address this issue. Specifically, we follow Charles and Hurst (2003) and Boserup et al. (2014) and include these measures for all generations used in the regressions.

Table 7 show regression results for the second generation, corresponding directly to our inheritance analysis in the previous section. Columns 1-3 report baseline estimates, first from an intergenerational wealth regression and then from intergenerational earnings and schooling regressions. The estimates are similar to the correlations presented by Lindahl et al. (2015). ${ }^{47}$

Human capital variables are then included as additional controls in the wealth estimations; earnings in column 4, schooling in column 5 and both earnings and schooling in column 6 . These controls reduce the intergenerational wealth estimate from 0.29 to $0.21-0.23$, i.e., by around one-fourth. This result differs from Boserup et al. (2014), which found that their wealth correlations where not affected by including similar controls. Comparing this with the inheritance analysis above suggests a fairly consistent picture, with the relative importance of inheritance for intergenerational wealth transmission being at least 50 per cent and human capital-related factors representing 25 per cent.

\section{[Insert Table 6 about here]}

We have also regressed the (inheritance-) purged wealth measure used in the previous section on the schooling and earnings measures of parents and children (see Online Appendix Table 11). We then find zero rank-rank wealth correlations, which is what we would expect if inher-

\footnotetext{
${ }^{47}$ They are not identical, as samples and variable definitions differ somewhat. Note that the earnings associations here are lower than in Lindahl et al. (2015) because we now use family earnings (instead of father's earnings).
} 
itance plays a very important role for the intergenerational wealth rank correlations (which is what we find in Tables 5 and 6). Note that this is also consistent with that controlling for inheritances removes those mediating channels that work through education and earnings.

In Online Appendix Table 12 we also report third-generation mediating variables regressions, on parental and grandparental variables. Only including parental variables, the child-parent wealth rank estimate decreases by 25 per cent, which exactly confirms the results reported in Table 7. Mechanisms related to human capital and labor productivity can therefore not explain the increase in the parent-child wealth estimate over time as observed in Table 2. Also including grandparental variables, the child-parent wealth rank estimate is unchanged, whereas the conditional child-grandparent wealth rank correlation decreases from a positive (but statistically insignificant) estimate to an estimate very close to zero.

\section{Conclusions}

We have estimated multigenerational wealth models using a unique data set, partly compiled specifically for this study, that enables us to improve on previous studies. First, we estimate models for two and three generations measuring wealth in mid-life for all three generations. Second, using matched data on bequests we are the first to directly measure the importance of this specific channel for the intergenerational transmission of wealth. Third, we present evidence on four-generational wealth transmissions, observing wealth of great grandchildren at a time when they have not yet entered the labour market. In addition to these contributions, we use high quality data on education attainment and lifetime earnings for three generations to compare our multigenerational wealth estimates to estimates for other outcomes as well as to decompose multigenerational wealth transmission into parts due to education and earnings, and other factors.

Our main findings are twofold. First, we find that grandparents' wealth is strongly associated with grandchildren's wealth, but that most of the association is mediated by parents' wealth. Grandparents' wealth seems to matter for an individual's wealth status also conditional on parents' wealth, but the estimated effect is relatively small. We predict that long-run wealth mobility is lower than what is predicted by a standard AR(1) model, but by a magnitude that suggest higher mobility than for most previous studies using data on education (Lindahl et al., 2015) and occupation (Long and Ferrie, 2013). We believe that we can rule out that measure- 
ment error in wealth for the first generation drives this result. Instead we argue that these differences are partly due to different mechanisms between wealth and the other outcomes.

Second, we observe a strikingly large role for inheritances in explaining intergenerational wealth transmission. The estimates indicate that at least half of wealth persistence is accounted for by direct transfers from parents (and grandparents). If correct, these results profoundly change our understanding of what drives mobility in the wealth distribution. Furthermore, recent survey evidence indicates that the perceived fairness of a certain level of inequality and the extent to which interventions are called for to change it largely depend on how this situation has come about; in particular, the extent to which economic success is inherited or selfmade seems crucial (see, e.g., Mulligan, 1997; Arrow, Bowles and Durlauf, 1999; and Bowles and Gintis, 2002). Against this backdrop, a possible interpretation of our results is that policy measures aimed at levelling the distribution of inherited wealth, e.g., gift and inheritance taxation, are desirable from an equality of opportunity perspective.

\section{References}

Adermon, A., M. Lindahl and M Palme (2016), "Dynastic Human Capital, Inequality and Intergenerational Mobility, Mimeo, University of Gothenburg

Arrondel, L. and C. Grange (2006), "Transmission and inequality of wealth: An empirical study of wealth mobility from 1800 to 1938 in France", Journal of Economic Inequality 4: 209-232.

Arrow, K., S. Bowles, and S. Durlauf (1999), Meritocracy and Economic Inequality. Princeton, N.J.: Princeton University Press.

Becker, G. (1974). “A Theory of Social Interactions”. Journal of Political Economy 82: $1063-1094$.

Becker, G. S. and N. Tomes (1979). "An Equilibrium Theory of the Distribution of Income and Intergenerational Mobility." Journal of Political Economy 87(6): 1153-1189.

Black, S. and P. Devereux (2011). "Recent Developments in Intergenerational Mobility," in Handbook of Labor Economics, vol. 4B, eds. O. Ashenfelter and D. Card, 1487-1541. Amsterdam: Elsevier.

Black, S., P. Devereux, P. Lundborg and K. Majlesi (2015). "Poor Little Rich Kids? The Determinants of the Intergenerational Transmission of Wealth," IZA Discussion Papper No. 9227. 
Blanden, J., P. Gregg and L. McMillan (2007). "Accounting for Intergenerational Income Persistence: Noncognitive Skills, Ability and Education," Economic Journal 117(519): C43-C60.

Boserup, S. H., W. Kopczuk and C. T. Kreiner (2014). "Intergenerational Wealth Mobility: Evidence from Danish Wealth Records of Three Generations.” Working Paper, University of Copenhagen.

Boserup, S. H., W. Kopczuk and C. T. Kreiner (2016). "Intergenerational Wealth Formation over the Life Cycle: Evidence from Danish Wealth Records 1984-2013.” Working Paper, University of Copenhagen.

Bowles, S. and H. Gintis (2002). "The inheritance of inequality". Journal of Economic Perspectives 16(3): 3-30.

Braun, S. and J. Stuhler (2014) "The Transmission of Inequality Across Multiple Generations: Testing Recent Theories with Evidence from Germany" Mimeo, November 2014, Universidad Carlos III de Madrid.

Charles, K. K. and E. Hurst (2003). "The Correlation of Wealth Across Generations". Journal of Political Economy 111(6): 1155-1182.

Chetty, R., N. Hendren, P. Kline and E. Saez (2014). "Where is the Land of Opportunity? The Geography of Intergenerational Mobility in the United States," Quarterly Journal of Economics 129(4): 1553-1623.

Clark, G. (2012). "What is the True Rate of Social Mobility in Sweden? A Surname Analysis, 1700-2012.” Mimeo. Davis: University of California, Davis.

Clark, G. (2014). The Son Also Rises: Surnames and the History of Social Mobility, Princeton, NJ: Princeton University Press.

Clark, G. and N. Cummins (2014) "Intergenerational Wealth Mobility in England, 19582012: Surnames and Social Mobility". Economic Journal 125(582): 61-85.

Elinder, M., O. Erixson and D. Waldenström (2016). "Inheritance and wealth inequality: Evidence from population registers." CEPR Discussion Paper.

Fagereng, A., M. Mogstad and M. Rønning (2015). "Why do wealthy parents have wealthy children? Mimeo. Statistics Norway.

Haider, Steven and Gary Solon (2006). "Life-Cycle Variation in the Association between Current and Lifetime Earnings." American Economic Review 96(4): 1308-1320.

Hallgren, Siver. (1939). Intelligens och miljö. En experimentell undersökning av barn i tredje skolåret vid Malmö folkskolor och privata skolor. Licentiate dissertation. Lund: Lund University.

Henrekson, M. and D. Waldenström (2016). "Inheritance Taxation in Sweden, 1885-2004: The Role of Ideology, Family Firms and Tax Avoidance." Economic History Review 
Kotlikoff, L. and L. Summers (1981). "The Role of Intergenerational Transfers in Aggregate Capital Accumulation.” Journal of Political Economy 89: 706-732.

Lindahl, M., M. Palme, S. Sandgren Massih, and A. Sjögren (2015) "Long-term intergenerational persistence of human capital: an empirical analysis of four generations" Journal of Human Resources 50(1): 1-33.

Long, J. and J. Ferrie (2013). "Intergenerational Occupational Mobility in Great Britain and the United States since 1850." American Economic Review 103(4): 1109-1137.

Menchik, P. L. (1979). "Inter-generational Transmission of Inequality: An Empirical Study of Wealth Mobility”. Economica 46(184): 349-362.

Modalsli, J. (2016). "Intergenerational mobility in Norway, 1865-2011". Forthcoming in Scandinavian Journal of Economics.

Modigliani, F. (1988). "The Role of Intergenerational Transfers and Life Cycle Savings in the Accumulation of Wealth", Journal of Economic Perspectives 2(2): 15-40.

Møllegaard, S. and M. M. Jæger (2015). "The Effect of Grandparents' Economic, Cultural, and Social Capital on Grandchildren's Educational Success." Research in Social Stratification and Mobility 42: 11-19.

Mulligan, C. (1997). Parental Priorities and Economic Inequality, University of Chicago Press, Chicago.

Ohlsson, H., J. Roine, D. Waldenström (2014). "Inherited wealth over the path of development: Sweden, 1810-2010”, Working Paper, Uppsala University.

Palme, M. and S. Sandgren (2008). "Parental Income, Lifetime Income, and Mortality." Journal of the European Economic Association 6(4): 890-911.

Pence, K. M. (2006). "The Role of Wealth Transformations: An Application to Estimating the Effect of Tax Incentives on Saving.” The B.E. Journal of Economic Analysis \& Policy 5(1)

Pfeffer, F. T. and A. A. Killewald (2015). "How Rigid Is the Wealth Structure and Why? Inter- and Multigenerational Associations in Family Wealth." PSC Research Report No. 15845 .

Piketty, T. (2011). “On the Long-Run Evolution of Inheritance: France 1820-2050” Quarterly Journal of Economics 126(3): 1071-1131.

Piketty, T. (2014), Capital in the 21st century, Belknap, Cambridge, MA.

Piketty, T. and G. Zucman (2014), "Capital is Back: Wealth-Income Ratios in Rich Countries, 1700-2010”. Quarterly Journal of Economics 129(3): 1255-1310.

Piketty, T. and G. Zucman (2015). "Wealth and Inheritance in the Long Run." in: Atkinson, A.B. and F. Bourguignon (Eds.), Handbook of Income Distribution. Vol. 2. Amsterdam: Elsevier. 
Roine, J. and D. Waldenström (2009). "Wealth Concentration over the Path of Development: Sweden, 1873-2006”. Scandinavian Journal of Economics 111(1): 151-187.

Royston, P. and D. G. Altman (1994). "Regression Using Fractional Polynomials of Continuous Covariates: Parsimonious Parametric Modelling." Journal of the Royal Statistical Society. Series C (Applied Statistics) 43(3): 429-67.

Solon, G. (1999). "Intergenerational Mobility in the Labor Market." in: O. Ashenfelter and D. Card (Eds.), Handbook of Labor Economics, Vol. 3. Amsterdam: Elsevier.

Solon, G. (2014). "Theoretical Models of Inequality Transmission across Multiple Generations.” Researsh in Social Stratification and Mobility 35: pp. 13-18.

Solon, G. (2015). "What Do We Know So Far about Multigenerational Mobility?" WP No. 21053, NBER.

SOU (1969). Kapitalbeskattningen. Betänkande av Kapitalskatteberedningen, SOU 1969:54, Norstedt, Stockholm.

Statistics Sweden (1949). Folkräkningen den 31 december 1945. 3, Partiella undersökningar (tolvtedelssamplingen), 2, Behandlar delar av statistiken över förmögenhet. Stockholm: Statistiska Centralbyrån.

Stuhler, J. (2013). "Mobility Across Multiple Generations: The Iterated Regression Fallacy." IZA Working Paper 7072.

Wahl, J. B. (2002). "From Riches to Riches: Intergenerational Transfers and the Evidence from Estate Tax Returns". Social Science Quarterly 84(2): 278-296.

de Wolff, P. and A. R. D. van Slijpe (1973). "The Relation between Income, Intelligence, Education and Social Background”. European Economic Review 4(3): 235-264.

Wolff, E. N. and M. Gittleman (2014). "Inheritances and the distribution of wealth or whatever happened to the great inheritance boom?". Journal of Economic Inequality 12(4): 439468. 
Table 1a: Summary statistics: Wealth distribution

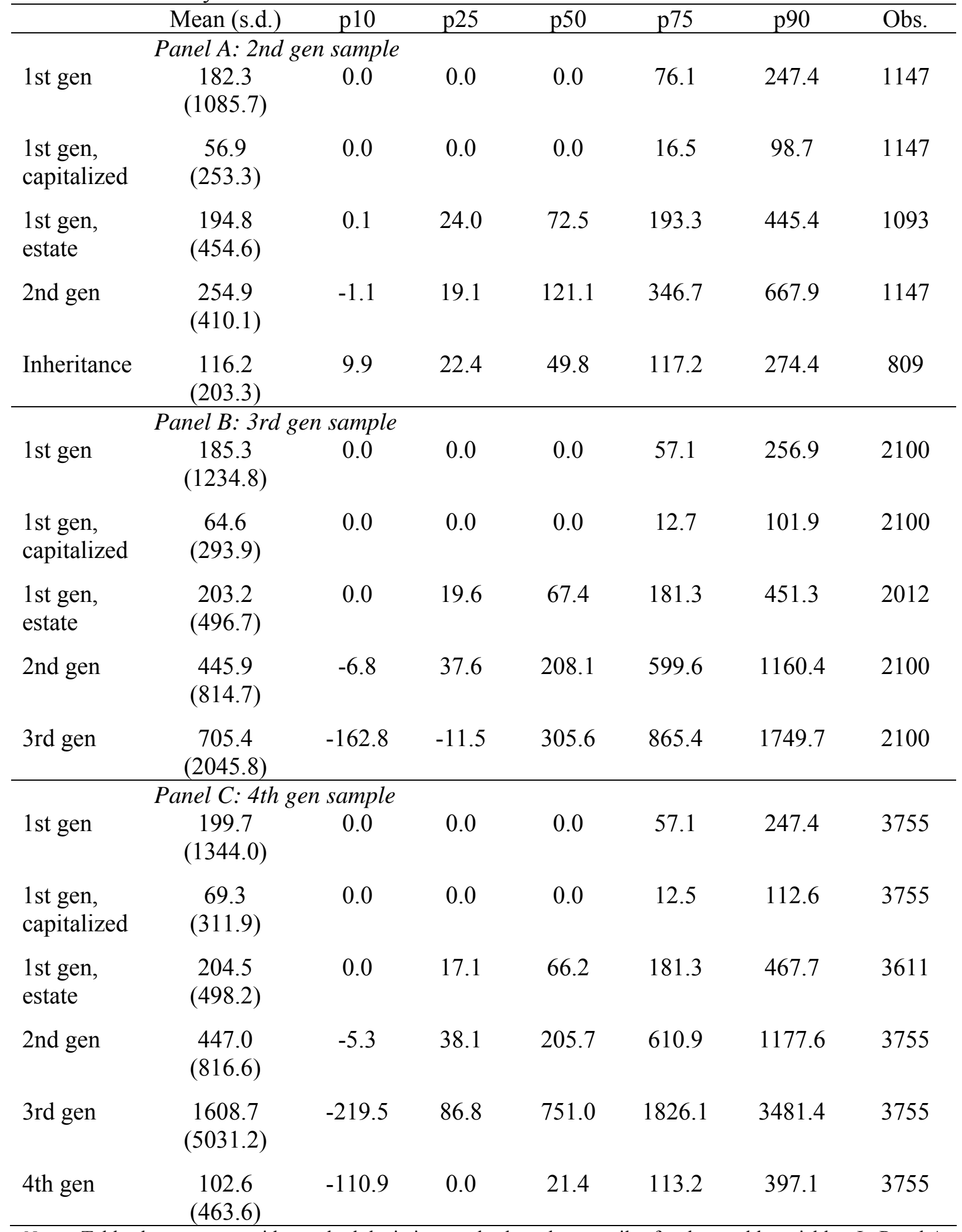

Notes: Table shows means with standard deviations and selected percentiles for the wealth variables. In Panel A variables are individual-level for the 2nd generation and family-level for the 1st generation; in Panel B variables are individual-level for the 3rd generation and family-level for previous generations; and in Panel C variables are individual-level for the 4th generation and family-level for previous generations. 
Table 1b: Summary statistics: covariates

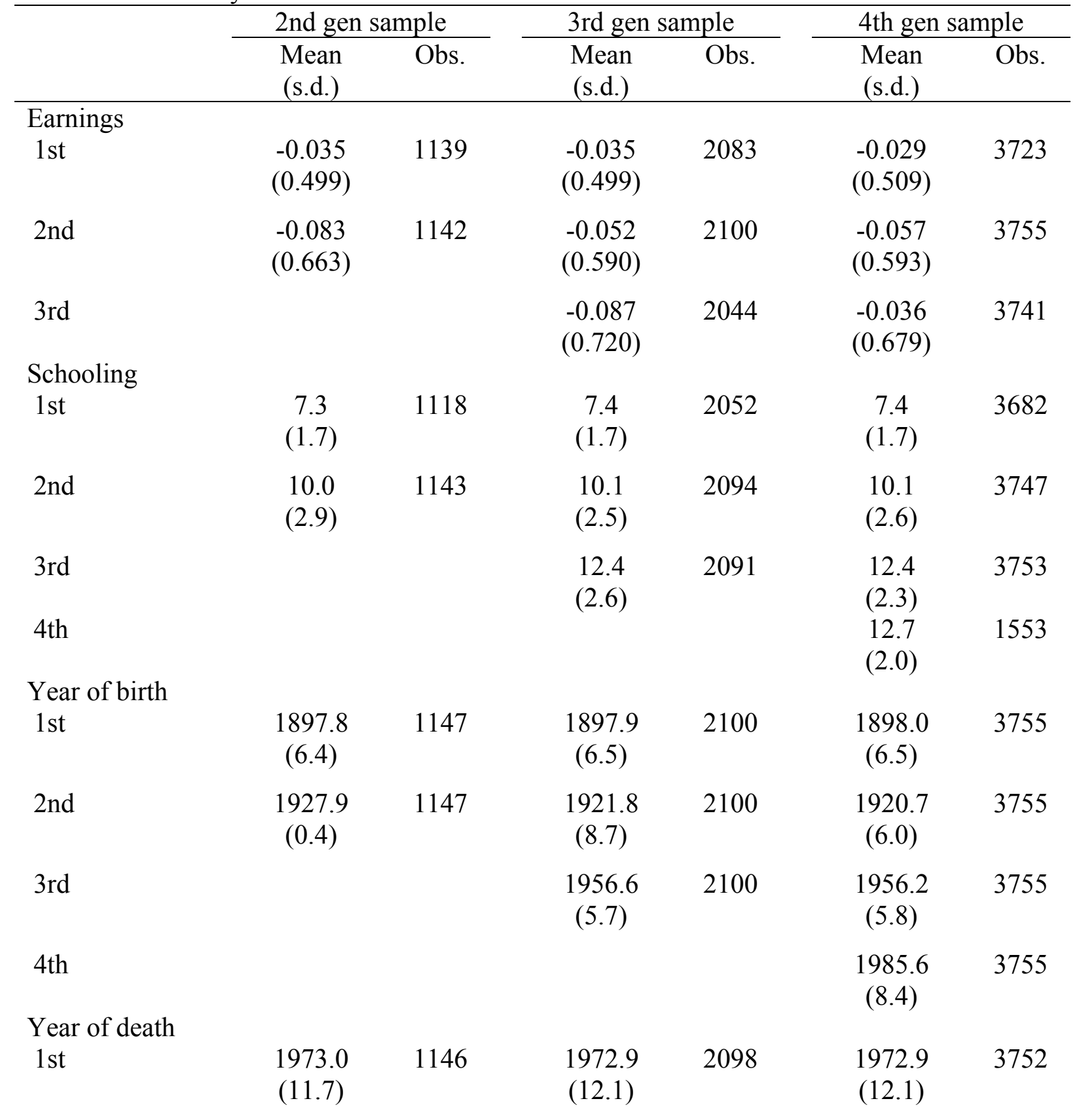

Notes: Table shows means with standard deviations for residualised log earnings, years of schooling, and years of birth and death. In the first set of columns variables are individual-level for the 2nd generation and familylevel for the 1st generation; in the second set of columns variables are individual-level for the 3rd generation and family-level for previous generations; and in the third set of columns variables are individual-level for the 4th generation and family-level for previous generations. 
Table 2: Wealth regressions

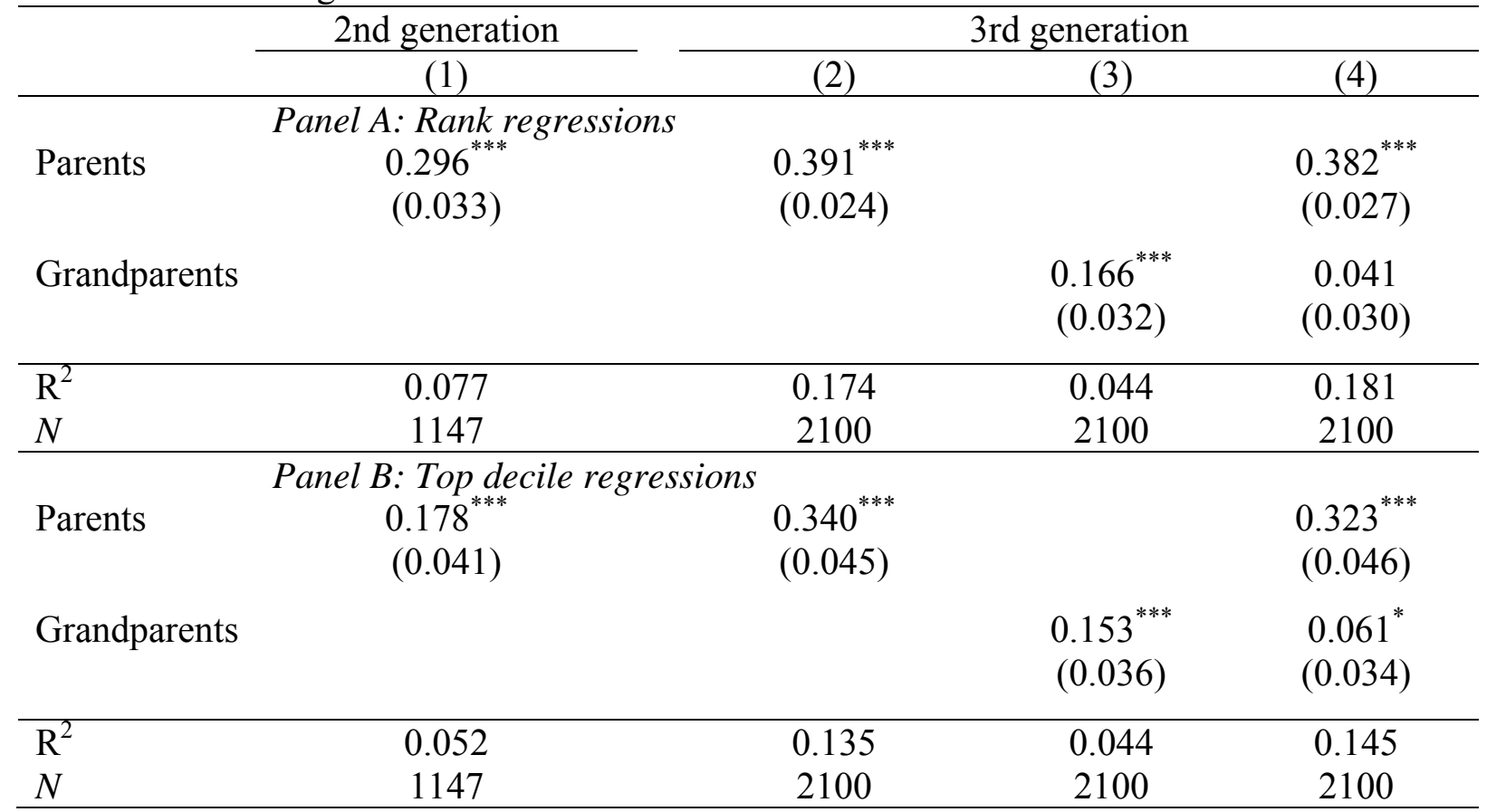

Notes: Standard errors in parentheses are clustered on family. Dependent variable is 2nd generation tax-register wealth in column 1, and 3rd generation tax-register wealth in columns 2-4. Explanatory variables are tax-register wealth for parents and grandparents. In panel A, all wealth variables have been percentile ranked within birth cohort groups. In panel B, all wealth variables are dummy variables equal to one for individuals in the top 10 per cent of the wealth distribution within their birth cohort group, and zero otherwise. All regressions include birth cohort group dummies for all generations. ${ }^{*} p<0.10,{ }^{* *} p<0.05,{ }^{* * *} p<0.01$. 
Table 3: Wealth regressions, alternative measures for 1st generation

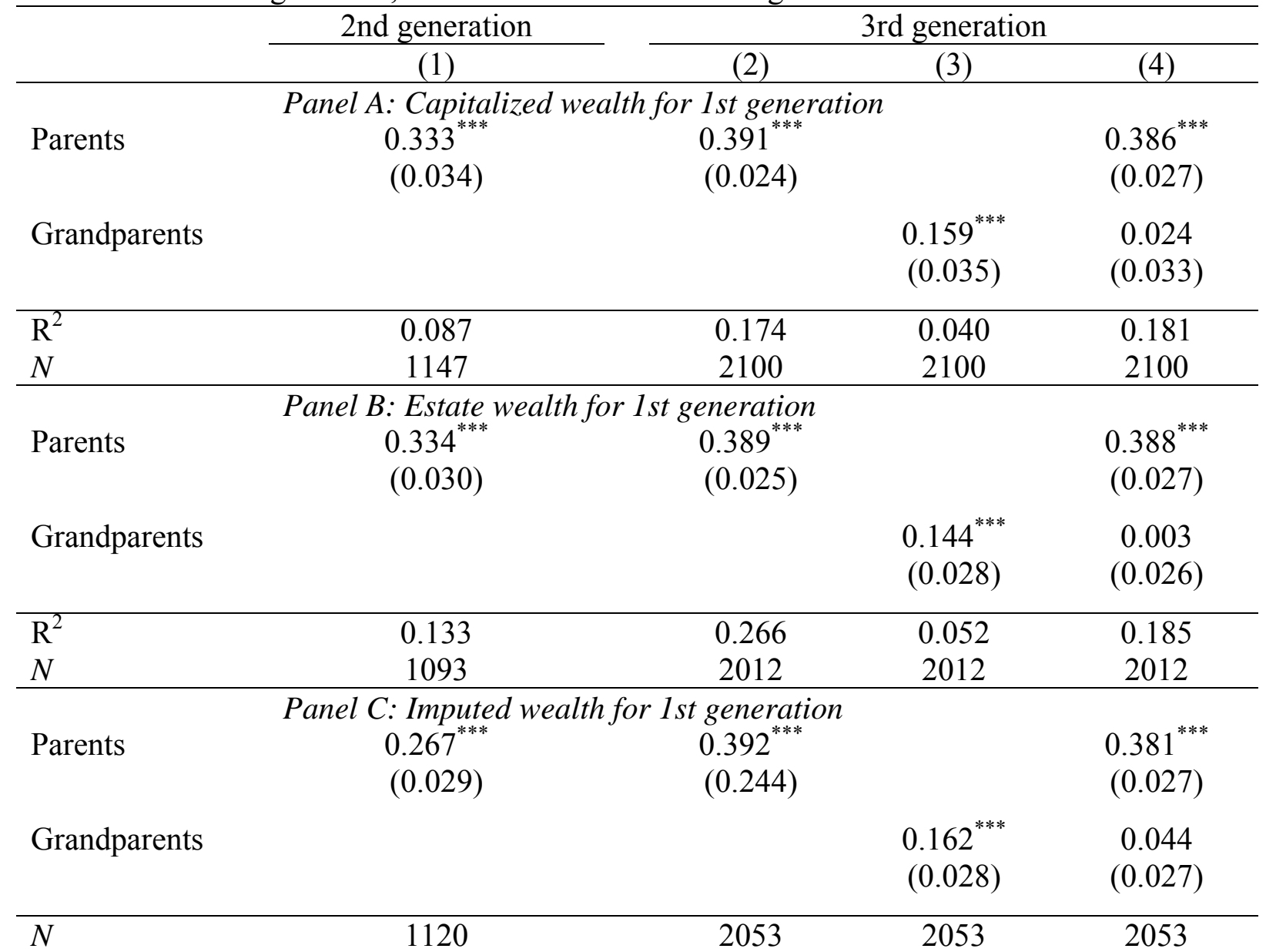

Notes: Standard errors in parentheses are clustered on family. Dependent variable is 2 nd generation tax-register wealth in column 1, and 3rd generation tax-register wealth in columns 2-3. Explanatory variables are tax-register wealth for parents and grandparents in panel A. 1st generation wealth (parents in column 1, grandparents in columns 2-3) is calculated from capital income information in panel A; it is wealth at death from estate records in panel B; and in panel $\mathrm{C}$ the censored observations of the wealth variable have been imputed (see text for details). Note that the estimates in column 2 are not affected by the alternative wealth measures, but that they deviate from the baseline estimate because of small variations in the samples. All wealth variables are percentile ranked within birth cohort groups, and all regressions include birth cohort group dummies for both generations. ${ }^{*}$ $p<0.10,{ }^{* *} p<0.05,{ }^{* * *} p<0.01$. 
Table 4: 4th generation wealth regressions

\begin{tabular}{|c|c|c|c|c|c|}
\hline & (1) & (2) & (3) & (4) & (5) \\
\hline Parents & $\begin{array}{c}\text { Panel A: } \\
0.387^{* * *} \\
(0.022)\end{array}$ & sample & & $\begin{array}{l}0.350^{* * *} \\
(0.023)\end{array}$ & $\begin{array}{l}0.352^{* * *} \\
(0.023)\end{array}$ \\
\hline Grandparents & & $\begin{array}{l}0.222^{* * *} \\
(0.026)\end{array}$ & & $\begin{array}{l}0.103^{* * *} \\
(0.024)\end{array}$ & $\begin{array}{c}0.111^{* * *} \\
(0.025)\end{array}$ \\
\hline Great grandparents & & & $\begin{array}{l}0.104^{* * *} \\
(0.030)\end{array}$ & & $\begin{array}{c}-0.005 \\
(0.026)\end{array}$ \\
\hline $\begin{array}{l}\mathrm{R}^{2} \\
N\end{array}$ & $\begin{array}{l}0.160 \\
3755\end{array}$ & $\begin{array}{l}0.061 \\
3755\end{array}$ & $\begin{array}{l}0.027 \\
3755\end{array}$ & $\begin{array}{l}0.175 \\
3755\end{array}$ & $\begin{array}{l}0.190 \\
3755\end{array}$ \\
\hline Parents & $\begin{array}{c}\text { Panel B: } \\
0.519^{* * *} \\
(0.032)\end{array}$ & 8 and yo & & $\begin{array}{l}0.472^{* * *} \\
(0.033)\end{array}$ & $\begin{array}{c}0.478^{* * *} \\
(0.032)\end{array}$ \\
\hline Grandparents & & $\begin{array}{l}0.300^{* * *} \\
(0.039)\end{array}$ & & $\begin{array}{c}0.141^{* * *} \\
(0.033)\end{array}$ & $\begin{array}{c}0.143^{* * *} \\
(0.035)\end{array}$ \\
\hline Great grandparents & & & $\begin{array}{l}0.131^{* * *} \\
(0.042)\end{array}$ & & $\begin{array}{c}-0.030 \\
(0.035)\end{array}$ \\
\hline $\begin{array}{l}\mathrm{R}^{2} \\
N\end{array}$ & $\begin{array}{c}0.297 \\
1657\end{array}$ & $\begin{array}{c}0.118 \\
1657\end{array}$ & $\begin{array}{c}0.054 \\
1657\end{array}$ & $\begin{array}{c}0.331 \\
1657\end{array}$ & $\begin{array}{c}0.360 \\
1657\end{array}$ \\
\hline Parents & $\begin{array}{c}\text { Panel C: } \\
0.269^{* * *} \\
(0.027)\end{array}$ & than 18 & & $\begin{array}{l}0.243^{* * *} \\
(0.028)\end{array}$ & $\begin{array}{c}0.250^{* * *} \\
(0.028)\end{array}$ \\
\hline Grandparents & & $\begin{array}{l}0.154^{* * *} \\
(0.029)\end{array}$ & & $\begin{array}{l}0.073^{* *} \\
(0.029)\end{array}$ & $\begin{array}{l}0.078^{* * *} \\
(0.029)\end{array}$ \\
\hline Great grandparents & & & $\begin{array}{c}0.066^{*} \\
(0.034)\end{array}$ & & $\begin{array}{l}-0.001 \\
(0.031)\end{array}$ \\
\hline $\begin{array}{l}\mathrm{R}^{2} \\
N\end{array}$ & $\begin{array}{l}0.084 \\
2098\end{array}$ & $\begin{array}{l}0.035 \\
2098\end{array}$ & $\begin{array}{c}0.021 \\
2098\end{array}$ & $\begin{array}{l}0.095 \\
2098\end{array}$ & $\begin{array}{l}0.112 \\
2098\end{array}$ \\
\hline
\end{tabular}

Notes: Standard errors in parentheses are clustered on family. Dependent variable is 4th generation tax-register wealth. Explanatory variables are tax-register wealth for parents, grandparents, and great grandparents. All wealth variables are percentile ranked within birth cohort groups, and all regressions include birth cohort group dummies for all included generations. ${ }^{*} p<0.10,{ }^{* *} p<0.05,{ }^{* * *} p<0.01$. 
Table 5: Inheritance regressions

\begin{tabular}{|c|c|c|c|c|c|c|}
\hline & \multicolumn{3}{|c|}{ One or two parents bequeathing } & \multicolumn{3}{|c|}{ Two parents bequeathing } \\
\hline & (1) & $(2)$ & (3) & $(4)$ & $(5)$ & $(6)$ \\
\hline Parents' wealth & & $\begin{array}{l}0.262^{* * *} \\
(0.039)\end{array}$ & $\begin{array}{c}0.116^{* * *} \\
(0.044)\end{array}$ & & $\begin{array}{c}0.310^{* * * *} \\
(0.054)\end{array}$ & $\begin{array}{l}0.144^{* *} \\
(0.068)\end{array}$ \\
\hline Inheritance & $\begin{array}{l}0.318^{* * *} \\
(0.033)\end{array}$ & & $\begin{array}{l}0.258^{* * *} \\
(0.038)\end{array}$ & $\begin{array}{l}0.379^{* * *} \\
(0.057)\end{array}$ & & $\begin{array}{c}0.277^{* * *} \\
(0.073)\end{array}$ \\
\hline $\mathrm{R}^{2}$ & 0.120 & 0.071 & 0.140 & 0.144 & 0.113 & 0.181 \\
\hline$N$ & 809 & 809 & 809 & 386 & 386 & 386 \\
\hline
\end{tabular}

Notes: Standard errors in parentheses are clustered on family. Dependent variable is 2nd generation tax-register wealth in 1991. Explanatory variables are tax-register wealth for parents and total inheritance received from parents. Parent's wealth has been percentile ranked within birth cohort groups, and average inheritance has been percentile ranked within parental year of death groups. All regressions include birth and death cohort group dummies corresponding to the included variables.

${ }^{*} p<0.10,{ }^{* *} p<0.05,{ }^{* * *} p<0.01$ 
Table 6: Purged inheritance regressions

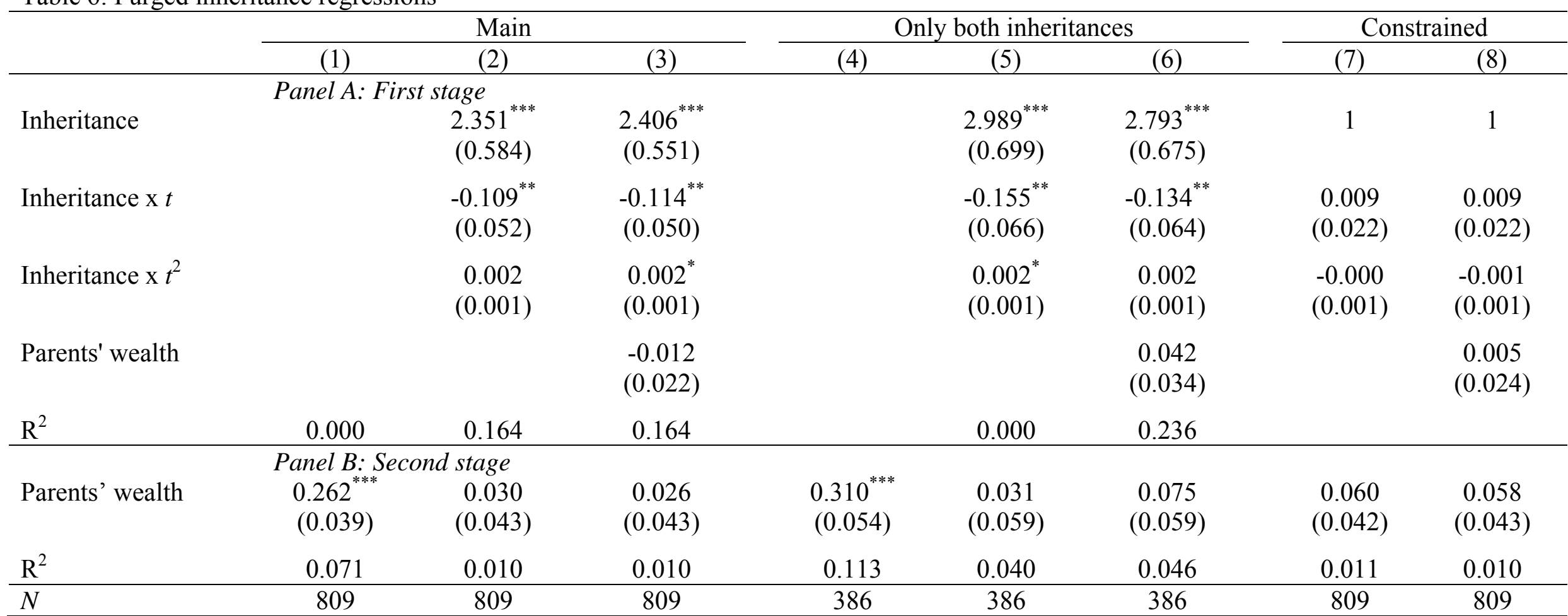

Notes: Standard errors in parentheses are clustered on family. Panel A shows regressions of 2nd generation wealth measured in 1991 on received inheritance and parental wealth. $t$ is the time in years between parents' average year of death and time when child wealth is measured. All variables in panel A are in levels. In panel B, the outcome variable is child wealth excluding inheritance, calculated as the predicted value from the first stage with the inheritance coefficients set to zero, and the residual added back in. In columns 4-6, only those who have received inheritances from both parents are included. In columns 7-8, the coefficient on inheritance in the first stage regression has been constrained to equal 1. Columns 1 and 4 show regressions using unadjusted child's wealth. In panel B, all regressions include birth cohort group dummies for both generations.

${ }^{*} p<0.10,{ }^{* *} p<0.05,{ }^{* * *} p<0.01$ 
Table 7: 2nd generation mediating variables regressions

\begin{tabular}{|c|c|c|c|c|c|c|}
\hline & \multirow{2}{*}{$\begin{array}{c}\text { Wealth } \\
\text { (1) }\end{array}$} & \multirow{2}{*}{$\begin{array}{l}\text { Earnings } \\
\text { (2) }\end{array}$} & \multirow{2}{*}{$\begin{array}{l}\text { Schooling } \\
\text { (3) }\end{array}$} & \multicolumn{3}{|c|}{ Wealth } \\
\hline & & & & (4) & $(5)$ & (6) \\
\hline Parents' wealth & $\begin{array}{c}0.288^{* * * *} \\
(0.034)\end{array}$ & & & $\begin{array}{l}0.226^{* * *} \\
(0.035)\end{array}$ & $\begin{array}{l}0.228^{* * *} \\
(0.034)\end{array}$ & $\begin{array}{l}0.209^{* * *} \\
(0.035)\end{array}$ \\
\hline Parents' earnings & & $\begin{array}{l}0.190^{* * *} \\
(0.030)\end{array}$ & & $\begin{array}{l}0.083^{* *} \\
(0.032)\end{array}$ & & $\begin{array}{c}0.050 \\
(0.033)\end{array}$ \\
\hline Parents' schooling & & & $\begin{array}{l}0.309^{* * *} \\
(0.031)\end{array}$ & & $\begin{array}{c}0.048 \\
(0.034)\end{array}$ & $\begin{array}{c}0.029 \\
(0.034)\end{array}$ \\
\hline Own earnings & & & & $\begin{array}{l}0.222^{* * *} \\
(0.030)\end{array}$ & & $\begin{array}{l}0.186^{* * *} \\
(0.031)\end{array}$ \\
\hline Own schooling & & & & & $\begin{array}{l}0.188^{* * *} \\
(0.032)\end{array}$ & $\begin{array}{c}0.117^{* * *} \\
(0.033)\end{array}$ \\
\hline $\mathrm{R}^{2}$ & 0.072 & 0.048 & 0.104 & 0.142 & 0.122 & 0.154 \\
\hline$N$ & 1103 & 1103 & 1103 & 1103 & 1103 & 1103 \\
\hline
\end{tabular}

Notes: Standard errors in parentheses are clustered on family. Dependent variable is 2nd generation tax-register wealth in columns 1 and 3-6, earnings in column 2, and schooling in column 3. Explanatory variables are parents' tax-register wealth, earnings, and schooling, and own earnings and schooling. All wealth variables are percentile ranked within birth cohort groups. Earnings is percentile ranked lifetime earnings, and schooling is percentile ranked years of completed schooling. All regressions include birth cohort group dummies for all included generations.

${ }^{*} p<0.10,{ }^{* *} p<0.05,{ }^{* * *} p<0.01$ 
$0.75-$

$0.50-$
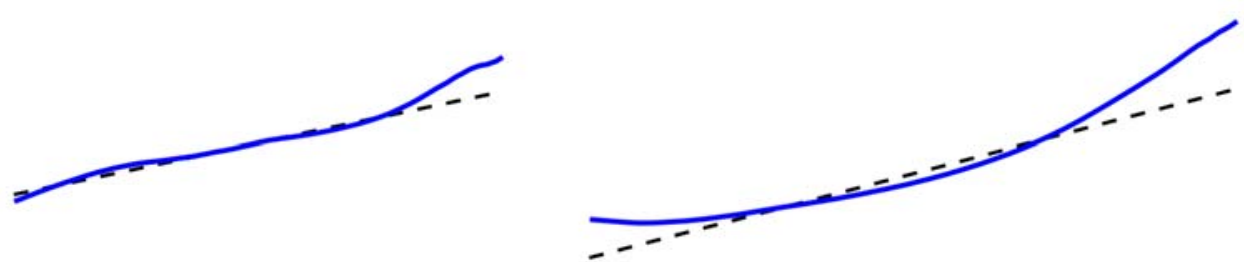

$0.25-$

$0.00-$

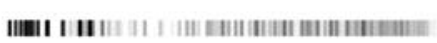

a) 2nd on parents

b) 3rd on parents

$1.00-$

$0.75-$

$0.50-$

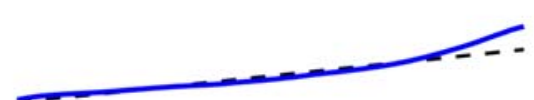

$0.25-$

$0.00-$

c) 3rd on grandparents

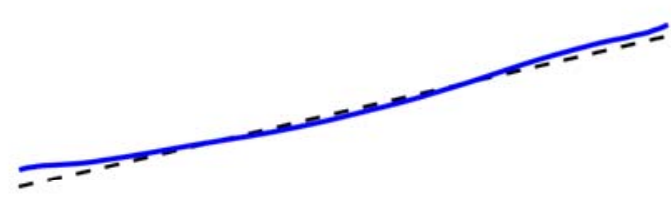

d) 4th on parents

$1.00-$

$0.75-$
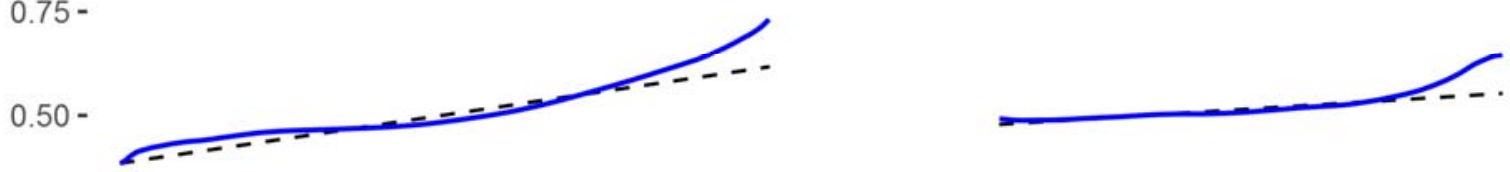

$0.25-$

$0.00-$

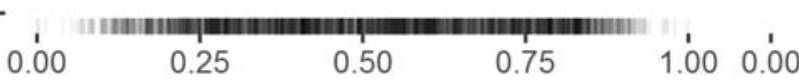

e) 4th on grandparents

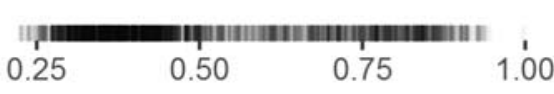

f) 4 th on great grandparents

\section{Figure 1: Kernel regressions}

Notes: Solid lines show results from bivariate local linear kernel regressions using an Epanechnikov kernel and 0.12 bandwidth. The $\mathrm{x}$ axis shows ancestors' wealth percentile rank, and the $\mathrm{y}$ axis shows descendants' wealth percentile rank. The variables have been residualised by regressing out birth cohort dummies for both generations, and the residuals have been rescaled to have the same range as the original percentile ranked variables. Dashed lines show best linear fits, and the vertical lines along the bottom show the distribution of observations across. Note that the lines stop at around the 25 th percentile in figures $1 \mathrm{a}, 1 \mathrm{c}$ and $1 \mathrm{f}$ because of the large number of observations with zero wealth in the first generation). 


\section{Appendix A Wealth measures}

\section{A1. Wealth measured during life}

\section{A1.1 First generation}

We measure wealth of the first generation (most born in the 1890s) at two points in time: 1945 and 1952. The observations were collected manually from the individual income and wealth tax records that are stored in the local county archives in Malmö (Malmö Stadsarkiv). Locating individuals in the income and wealth tax registers in this period is not uncomplicated, but requires parallel searches in address calendars (to get names of block and street address) and often different books containing the actual tax records.

For the 1945 observations, we use tax records (taxeringslängder) from 1946 showing incomes and wealth in 1945. During the period 1911-1946, this information is available in the income and tax register since personal wealth was taxed jointly with income. Specifically, one hundredth of taxable net wealth was added to taxable income; if net wealth was negative, nothing was added. For reasons of discretion, an individual's net wealth was not reported directly in the tax records, but for 1945 it is possible to back out taxable wealth from the reported income and deduction items (before income year 1945 tax register items were structured differently and do unfortunately not allow for this to be done). In the register, the reported item "taxable amount" $T$ (taxerat belopp) is the tax base. It equals the reported total gross income $Y$ (sammanräknad nettoinkomst) less the reported "general deductions" D (medgivna allmänna avdrag) plus the non-reported wealth share $\widetilde{W}$ (förmögenhetsandel), equal to $1 / 100$ of taxable net wealth $W$. Writing the taxable amount as $T=Y-D+\widetilde{W}$ and using the fact that we observe the first three terms in this equation in the tax register, we can retrieve the personal taxable net wealth $W=100 \cdot(T+D-Y)$. Note that exactly this procedure is the one used by Statistics Sweden when analyzing the wealth distribution for the Census of 1945 (Statistics Sweden, 1949, p. 2*).

Taxable wealth in 1952 is also collected manually from the tax registers. After a wealth tax reform in 1947, however, in this year wealth was taxed separately from income and we retrieve explicitly stated net wealth amounts from wealth tax registers (förmögenhetstaxeringslängder). In 1952, all households owning net assets worth at least 30,000 SEK had to hand in a wealth tax return. Approximately nine percent (329,000 out of 3.7 million) of Swedish households reported owning wealth above the taxable threshold, and in our population they were eight percent.

A detail to note is that this first-generation wealth cannot take negative values because of how the tax statistics are reported. In 1945, only non-negative wealth is allowed to contribute to the total taxable amount on the tax return, and in 1952 we only observe households with wealth above a tax threshold.

\section{A1.2 Second generation}

Wealth held by the second generation (mostly born in 1928) is in the form of taxable wealth observed in tax registers during the years 1985, 1988 and 1991 (thus measured at ages 57-63). Included in the wealth measure for 1985 and 1988 is the tax value of real estate, which is 75 percent of market value. Because we also have separate information on real estate tax value, we can scale this up to market value and add the difference to the wealth measure. This re- 
duces the number of zero (censored) observations by around 10 percentage points. This augmented measure is used in a sensitivity analysis.

In the first two years for which we measure wealth is censored from below at zero whereas this is not the case for the last year, the reason being different reporting routines at the tax authority after the Swedish tax reform of 1990-1991.

\section{A1.3 Third and fourth generations}

Third (born in the 1950s) generation's wealth is measured in 1999 and 2006 (thus measured at ages 43-50), and fourth generation's wealth (born in the 1980s) is measured in 2006 (around age 20). While these wealth data also stem from the wealth tax, they differ from the wealth tax return register data used for the first two generations by being partly based on third-party reported financial asset statements of banks and brokerage firms. The data comes from Statistics Sweden's Wealth Register which covers wealth statements for all individuals, i.e., not only households filing tax returns, in Sweden between 1999 and 2007.

All assets and liabilities in the Wealth Register are in current market prices, which is a difference which means that tax-assessed property values are multiplied by a sales price ratio (computed by Statistics Sweden using data on actual sales prices and tax assessments for homes sold) and reported in market values. Wealth observations cease in 2007 due to the repeal of the Swedish wealth tax in that year.

\section{A2. Wealth measured at death: Estate inventory reports}

For all deceased individuals in the first and second generations, we have collected estate wealth data. These records come from estate inventory reports (bouppteckningar) that the law mandates to be set up for each deceased individual with some assets. ${ }^{48}$ The reports contain information about civil status (years of marriage, remarriages), estate wealth composition (value of housing, life insurance savings), inter vivos gifts, wills, pre-nuptial agreements and inheritance waivers, generally for both father and mother. Up until 2001 the estate reports were filed with local courts and archived in one of Sweden's nine local county archives, and since 2001 they are filed at the tax authorities.

In order to locate a deceased individual's estate inventory report one needs to know the date and place of death, and we have retrieved this information from the original database and from the official death register in Sweden.

\section{A3. Inheritances}

Inheritances are observed when parents bequeathed wealth to their children in the second generation. We do not include inheritances from others than the parents, i.e., siblings, other relatives or non-relatives. Elinder, Erixson and Waldenström (2016) show that almost two thirds of inheritances in Sweden in the early 2000s come from parents.

An inheritance lot is calculated for each heir by the tax authorities and then reported in specific inheritance tax records (arvsskattestegar) which are filed with the local county archives

\footnotetext{
${ }^{48}$ For individuals without notable wealth, typically very young people, an estate notification (dödsboanmälan) is typically filed.
} 
until 2001 after which it is kept by the tax authorities. Typically, the tax record is also attached to each estate inventory report.

It should be noted that these inheritance lots were based on a close scrutiny of the probated wealth, accounting for wills if they existed and taxable inter vivos gifts made within ten years of the testator's death.

\section{Appendix B Earnings and Education}

Lifetime earnings are calculated by taking residuals from a regression of log earnings (for left-hand side variables) or log within-family average earnings (for right-hand side variables) on a quadratic in birth year and a full set of income year dummies. For the first generation, we observe earnings in 1929, 1933, 1937, 1938, and 1942; for the second and third generations, we observe earnings in 35 different years between 1948 and 2008, restricted to observations at age 23 and older for the second generation, and 27 and older for the third generation.

Our log earnings measure is constructed as from regressing log earnings on a cubic in birth year and year indicators (done separately by generation and gender), taking the residuals which then are averaged over years. Labor income is compiled from Swedish high quality registers for all years that we use. For the first generation we have access to income data as 5 yearly measures spanning 13 years, typically observed between ages 33 and 46 . For the second and third generations we can more or less observe lifetime earnings for most of the individuals. See Lindahl et al. (2015) for details.

There is no direct information on educational attainments for the first generation. However, since the 1938 survey contains detailed information on occupational status, the educational requirements for each occupation were constructed by the educational scientists who originally obtained the data. There are no education classifications available for the mothers of the index generation.

For the second to fourth generations, we have obtained data on educational attainments from the national education register. We mainly use information from 1985 for the second generation and from 2009 for the third and fourth generations. Years of schooling is constructed from educational levels available in registers for the second, third and fourth generations. With detailed information on completed level of education, we construct years of schooling as follows: seven for (old) primary school, nine for (new) compulsory schooling, 9.5 for (old) postprimary school (realskola), 11 for short high school, 12 for long high school, 14 for short university, 15.5 for long university, and 19 for a PhD. For more details, see Lindahl (2015).

\section{Appendix C Estimating the long-run intergenerational persistence in social status}

Clark (2012) and Clark and Cummins (2014) propose that intergenerational transmission of wealth is evolving as $w_{i t}=x_{i t}+u_{i t}$ and $x_{i t}=b x_{i t-1}+e_{i t}$. This should be interpreted as wealth mismeasuring $x$, the underlying "social status", and that the true value of wealth evolves as an AR(1) between generations. Clark and Cummins (2014) label the parameter $b$ as the long-run intergenerational persistence in social status and show that that if we estimate bivariate models between $n$ generations we get $E\left[\hat{\beta}_{n}\right]=\theta b^{n}$ where $\theta$ is the reliability ratio of $w$ in measuring $x$, and $\hat{\beta}_{n}$ is from the regression $w_{i t+n}=\beta_{0}+\beta_{n} w_{i t}+u_{i t+n}$. Hence, we get that $E\left[\hat{\beta}_{2}\right]=E\left[\hat{\beta}_{1}\right] b$, which is a formula that can be used to derive $b$ in the following way: 
divide the estimate from a regression of child's wealth on grandparents' wealth by an estimate from a regression of parent's wealth on grandparents' wealth. ${ }^{49}$

As pointed out in Solon (2015), this is just an instrumental variable estimate, where grandparents' wealth is used as an instrument parent's wealth in a regression of child's wealth on parent's wealth. If the simple model by Clark and Cummins (2014) fails to hold true (Solon, 2015 , lists a number of reasons for why this might be the case), this IV estimate is most likely (as argued in Lindahl, 2015) an upper bound estimate of $b$. To make use of the fact that we have family-linked data on three adjacent generations, we, in section 2.2.2 where we compare our results in Lindahl et al. (2015) with the results in the present paper, instead divide by the average of two estimates: the estimate from a regression of child and parents wealth and the estimate from a regression of parent's and grandparents' wealth. As pointed out in Braun and Stuhler (2015) this requires the additional assumption that measurement error in wealth is constant over the first two generations.

\section{Appendix D Estimating associations in the presence of mediating variables}

When we analyze the impact of inheritance, or bequests $(B)$, on the intergenerational association in wealth we must acknowledge that $B$ is a mediating variable. A common approach is to proceed by estimating models of the following form: ${ }^{50}$

$$
\begin{aligned}
& w_{i t}=\alpha_{0}+\rho_{1} w_{i t-1}+\varepsilon_{i t}, \\
& w_{i t}=\alpha_{0}^{\prime}+\rho_{2} w_{i t-1}+\varphi B_{i t}+v_{i t}, \\
& B_{i t}=\alpha^{\prime \prime}{ }_{0}+\rho_{3} w_{i t-1}+\mu_{i t},
\end{aligned}
$$

Under the strong assumption that $\operatorname{Cov}\left(v_{i t}, \mu_{i t}\right)=0$, which for example holds if $B_{i t}$ is exogenously determined conditional on $w_{i t-1}$, we can interpret $\rho_{1}-\rho_{2}$ as the role of inheritance (i.e., the mediating effect of inheritance) in the overall association of wealth across generations. This can be seen by inserting equation D.3 into D.2, which gives $\rho_{1}=\rho_{2}+\varphi \rho_{3}$. Hence, the intergenerational association in wealth between children and parents can be decomposed into one part that is due to the direct link with parent's wealth and another part which is due to an indirect effect working through the mediating variable $B_{i t}$.

Suppose that $B$ is not exogenously determined - for instance, if $\operatorname{Cov}\left(v_{i t}, \mu_{i t}\right)>0$, perhaps because there is another mediating variable $Z_{i t}$ which is positively correlated with the child's wealth and also with $B_{i t}$ (conditional on parental wealth). Intuitively, by controlling for $B_{i t}$ in equation D.2, we "over-control" for $B_{i t}$ in the sense that we control not only for $B_{i t}$, but also the part of $Z_{i t}$ that is correlated with $B_{i t}$. Hence, $\varphi$ will be overestimated and $\rho_{2}$, the direct channel linking parents' and child wealth, will be underestimated. It follows that $\rho_{1}-\rho_{2}$ and the importance of $B_{i t}$ as a mediating channel will be overestimated. An example of underestimating the importance of the inheritance channel would be if inheritances are poorly measured, in relation to parent's wealth.

\footnotetext{
${ }^{49}$ Braun and Stuhler (2014) show that the Clark-model has a number of testable implications such as this one, which they use to test the model on multigenerational data for Germany.

${ }^{50}$ See, for example, Blanden et al. (2007) who analyze a number of channels underlying the intergenerational persistence in income in the U.K.
} 
In testing the importance of inheritances for the intergenerational persistence in wealth, our first approach is simply to use ranked versions of the variables, and estimate $\rho_{1}$ and $\rho_{2}$. Our second approach utilizes the fact that if $B_{i t}$ is given just before wealth of the child is measured, we will have that $\varphi=1$ and hence $B_{i t}$ can be simply be subtracted from $w_{i t}$ to create an "inheritance-free" wealth variable $w_{i t}$ ' for the child generation which we then regress against can $w_{i t-1}$. In practice, we need to use the timing variation of inheritances and estimate a flexible version of equation D.2, and subtract the impact of inheritances on the wealth in the child generation. We then regress this "inheritance-free" measure of children's wealth on parental wealth to generate an alternative estimate of $\rho_{2}$, which we use to estimate $\rho_{1}-\rho_{2}$. An advantage with the second approach is that, if our model is correct, we do not need to estimate $\varphi$, but can simply assume that $\varphi=1$.

Note that when we investigate the importance of schooling and earnings for the intergenerational association in wealth, similar issues exists. An advantage is that we can then control for schooling and earnings in both generations, which is not possible for inheritances. 


\section{Online Appendix Tables and Figures}

Online Appendix Table 1: Wealth regressions, alternative definitions and measures

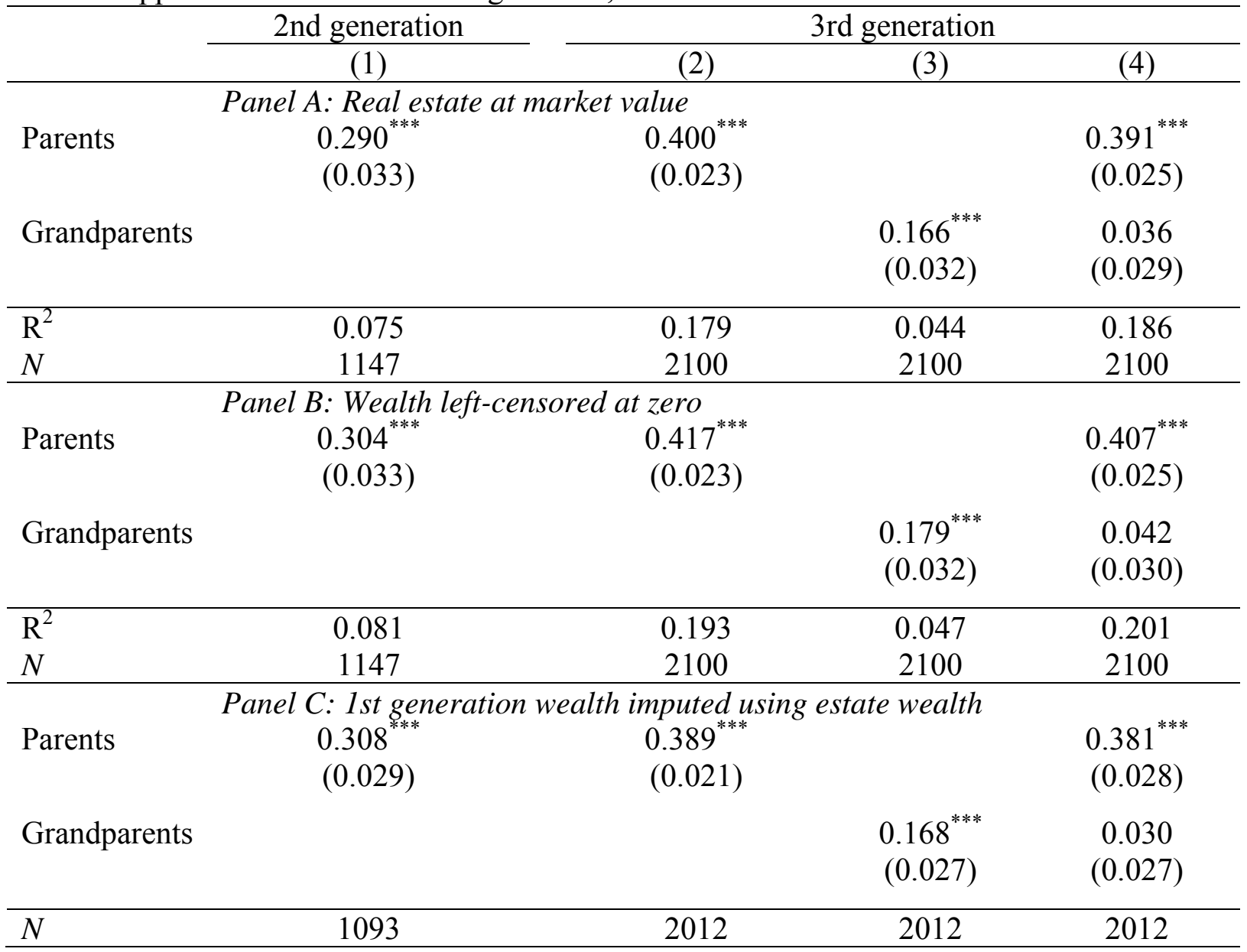

Notes: Standard errors in parentheses are clustered on family. Dependent variable is 2nd generation tax-register wealth in column 1, and 3rd generation tax-register wealth in columns 2-4. Explanatory variables are tax-register wealth for parents and grandparents. All wealth variables have been percentile ranked within birth cohort groups. In panel A, 2nd generation wealth is average of 1985 and 1988 wealth, where real estate has been scaled up to market value. In panel B, 2nd and 3rd generation wealth has been left-censored at zero. In panel C, zeroes in 1st generation wealth have been imputed using estate wealth. All regressions include birth cohort group dummies for all generations. ${ }^{*} p<0.10,{ }^{* *} p<0.05,{ }^{* * *} p<0.01$. 
Online Appendix Table 2: Summary statistics: ranked variables

\begin{tabular}{|c|c|c|c|c|c|c|c|c|c|}
\hline & \multicolumn{3}{|c|}{ 2nd gen sample } & \multicolumn{3}{|c|}{ 3rd gen sample } & \multicolumn{3}{|c|}{ 4th gen sample } \\
\hline & $\begin{array}{l}\text { Mean } \\
\text { (s.d.) }\end{array}$ & $\begin{array}{l}\text { Min } \\
\text { Max }\end{array}$ & Obs. & $\begin{array}{l}\text { Mean } \\
\text { (s.d.) }\end{array}$ & $\begin{array}{l}\text { Min } \\
\text { Max }\end{array}$ & Obs. & $\begin{array}{l}\text { Mean } \\
\text { (s.d.) }\end{array}$ & $\begin{array}{l}\text { Min } \\
\text { Max }\end{array}$ & Obs. \\
\hline $\begin{array}{l}\text { Wealth } \\
1 \mathrm{st}\end{array}$ & $\begin{array}{c}0.508 \\
(0.253)\end{array}$ & $\begin{array}{l}0.245 \\
0.996\end{array}$ & 1147 & $\begin{array}{c}0.500 \\
(0.248)\end{array}$ & $\begin{array}{l}0.217 \\
0.996\end{array}$ & 2100 & $\begin{array}{c}0.501 \\
(0.246)\end{array}$ & $\begin{array}{l}0.225 \\
0.998\end{array}$ & 3755 \\
\hline $\begin{array}{l}1 \text { st, } \\
\text { capitalized }\end{array}$ & $\begin{array}{c}0.504 \\
(0.240)\end{array}$ & $\begin{array}{l}0.289 \\
0.997\end{array}$ & 1147 & $\begin{array}{c}0.499 \\
(0.233)\end{array}$ & $\begin{array}{l}0.267 \\
0.994\end{array}$ & 2100 & $\begin{array}{c}0.500 \\
(0.232)\end{array}$ & $\begin{array}{l}0.246 \\
0.997\end{array}$ & 3755 \\
\hline $\begin{array}{l}\text { 1st, } \\
\text { estate }\end{array}$ & $\begin{array}{c}0.510 \\
(0.284)\end{array}$ & $\begin{array}{l}0.003 \\
0.997\end{array}$ & 1093 & $\begin{array}{c}0.499 \\
(0.284)\end{array}$ & $\begin{array}{l}0.003 \\
0.996\end{array}$ & 2012 & $\begin{array}{c}0.499 \\
(0.285)\end{array}$ & $\begin{array}{l}0.002 \\
0.997\end{array}$ & 3611 \\
\hline 2nd & $\begin{array}{c}0.504 \\
(0.286)\end{array}$ & $\begin{array}{l}0.001 \\
0.999\end{array}$ & 1147 & $\begin{array}{c}0.504 \\
(0.285)\end{array}$ & $\begin{array}{l}0.002 \\
0.998\end{array}$ & 2100 & $\begin{array}{c}0.504 \\
(0.287)\end{array}$ & $\begin{array}{l}0.001 \\
0.999\end{array}$ & 3755 \\
\hline $3 \mathrm{rd}$ & & & & $\begin{array}{c}0.499 \\
(0.288)\end{array}$ & $\begin{array}{l}0.002 \\
0.998\end{array}$ & 2100 & $\begin{array}{c}0.502 \\
(0.289)\end{array}$ & $\begin{array}{l}0.001 \\
0.998\end{array}$ & 3755 \\
\hline 4 th & & & & & & & $\begin{array}{c}0.506 \\
(0.289)\end{array}$ & $\begin{array}{l}0.002 \\
0.998\end{array}$ & 3755 \\
\hline $\begin{array}{l}\text { Earnings } \\
1 \mathrm{st}\end{array}$ & $\begin{array}{c}0.495 \\
(0.284)\end{array}$ & $\begin{array}{l}0.005 \\
0.997\end{array}$ & 1139 & $\begin{array}{c}0.500 \\
(0.286)\end{array}$ & $\begin{array}{l}0.003 \\
0.996\end{array}$ & 2083 & $\begin{array}{c}0.499 \\
(0.286)\end{array}$ & $\begin{array}{l}0.002 \\
0.995\end{array}$ & 3723 \\
\hline 2nd & $\begin{array}{c}0.509 \\
(0.285)\end{array}$ & $\begin{array}{l}0.001 \\
0.999\end{array}$ & 1142 & $\begin{array}{c}0.509 \\
(0.281)\end{array}$ & $\begin{array}{l}0.002 \\
0.996\end{array}$ & 2100 & $\begin{array}{c}0.506 \\
(0.282)\end{array}$ & $\begin{array}{l}0.001 \\
0.999\end{array}$ & 3755 \\
\hline $3 \mathrm{rd}$ & & & & $\begin{array}{c}0.507 \\
(0.289)\end{array}$ & $\begin{array}{l}0.002 \\
0.998\end{array}$ & 2044 & $\begin{array}{c}0.507 \\
(0.286)\end{array}$ & $\begin{array}{l}0.001 \\
0.998\end{array}$ & 3741 \\
\hline $\begin{array}{l}\text { Schooling } \\
1 \mathrm{st}\end{array}$ & $\begin{array}{c}0.502 \\
(0.265)\end{array}$ & $\begin{array}{l}0.011 \\
0.993\end{array}$ & 1118 & $\begin{array}{c}0.502 \\
(0.263)\end{array}$ & $\begin{array}{l}0.012 \\
0.995\end{array}$ & 2052 & $\begin{array}{c}0.499 \\
(0.262)\end{array}$ & $\begin{array}{l}0.019 \\
0.993\end{array}$ & 3682 \\
\hline $2 n d$ & $\begin{array}{c}0.497 \\
(0.285)\end{array}$ & $\begin{array}{l}0.162 \\
0.999\end{array}$ & 1143 & $\begin{array}{c}0.501 \\
(0.280)\end{array}$ & $\begin{array}{l}0.038 \\
0.996\end{array}$ & 2094 & $\begin{array}{c}0.503 \\
(0.282)\end{array}$ & $\begin{array}{l}0.059 \\
0.998\end{array}$ & 3747 \\
\hline $3 \mathrm{rd}$ & & & & $\begin{array}{c}0.505 \\
(0.283)\end{array}$ & $\begin{array}{l}0.002 \\
0.997\end{array}$ & 2091 & $\begin{array}{c}0.503 \\
(0.287)\end{array}$ & $\begin{array}{l}0.001 \\
0.998\end{array}$ & 3753 \\
\hline 4 th & & & & & & & $\begin{array}{c}0.500 \\
(0.278)\end{array}$ & $\begin{array}{l}0.003 \\
0.996\end{array}$ & 1553 \\
\hline
\end{tabular}

Notes: Table shows means with standard deviations, minimum and maximum values for percentile ranked variables. In the first set of columns variables are individual-level for the 2 nd generation and family-level for the 1st generation; in the second set of columns variables are individual-level for the 3rd generation and family-level for previous generations; and in the third set of columns variables are individual-level for the 4th generation and family-level for previous generations. 
Online Appendix Table 3: Top percentile group regressions, alternative cutoffs

\begin{tabular}{|c|c|c|c|c|}
\hline & \multirow{2}{*}{$\begin{array}{c}\text { 2nd generation } \\
\text { (1) }\end{array}$} & \multicolumn{3}{|c|}{ 3rd generation } \\
\hline & & $(2)$ & (3) & $(4)$ \\
\hline Parents & $\begin{array}{l}\text { Panel A: Top five percent } \\
0.226^{* * *} \\
(0.0585)\end{array}$ & $\begin{array}{l}0.349^{* * *} \\
(0.0638)\end{array}$ & & $\begin{array}{l}0.332^{* * *} \\
(0.0627)\end{array}$ \\
\hline Grandparents & & & $\begin{array}{l}0.133^{* * *} \\
(0.0458)\end{array}$ & $\begin{array}{c}0.0529 \\
(0.0383)\end{array}$ \\
\hline $\mathrm{R}^{2}$ & 0.062 & 0.131 & 0.047 & 0.144 \\
\hline$N$ & 1147 & 2100 & 2100 & 2100 \\
\hline Parents & $\begin{array}{c}\text { Panel B: Top } 15 \text { percent } \\
0.192^{* * *} \\
(0.0360)\end{array}$ & $\begin{array}{l}0.321^{* * *} \\
(0.0374)\end{array}$ & & $\begin{array}{l}0.306^{* * *} \\
(0.0384)\end{array}$ \\
\hline Grandparents & & & $\begin{array}{l}0.151^{* * *} \\
(0.0318)\end{array}$ & $\begin{array}{c}0.0831^{* * *} \\
(0.0302)\end{array}$ \\
\hline $\mathrm{R}^{2}$ & 0.057 & 0.121 & 0.045 & 0.137 \\
\hline$N$ & 1147 & 2100 & 2100 & 2100 \\
\hline
\end{tabular}

Notes: Standard errors in parentheses are clustered on family. All variables are dummy variables equal to one for individuals in the top of the wealth distribution within their birth cohort group, and zero otherwise. tax-register wealth for parents and grandparents. In panel A, the dummies indicate the top five percent, and in panel B, they indicate the top 15 percent. All regressions include birth cohort group dummies for all generations.

${ }^{*} p<0.10,{ }^{* *} p<0.05,{ }^{* * *} p<0.01$. 
Online Appendix Table 4: Wealth regressions, three-generation panel

\begin{tabular}{|c|c|c|c|c|}
\hline & \multirow{2}{*}{$\begin{array}{c}\text { 2nd generation } \\
\text { (1) }\end{array}$} & \multicolumn{3}{|c|}{ 3rd generation } \\
\hline & & $(2)$ & (3) & (4) \\
\hline Parents & $\begin{array}{c}0.292^{* * *} \\
(0.037)\end{array}$ & $\begin{array}{c}0.390^{* * *} \\
(0.026)\end{array}$ & & $\begin{array}{c}0.388^{* * *} \\
(0.027)\end{array}$ \\
\hline Grandparents & & & $\begin{array}{c}0.136^{* * *} \\
(0.033)\end{array}$ & $\begin{array}{c}0.040 \\
(0.031)\end{array}$ \\
\hline $\mathrm{R}^{2}$ & 0.079 & 0.171 & 0.046 & 0.187 \\
\hline$N$ & 920 & 1939 & 1939 & 1939 \\
\hline
\end{tabular}

Notes: The sample is restricted to only include families where we have wealth observations on all three generations. In column 1, only individuals who have children with observed wealth in the 3rd generation are included, and in columns $2-4$, only individuals who have a parent in the index generation with observed wealth, as well as grandparents with observed wealth, are included. Standard errors in parentheses are clustered on family. Dependent variable is 2 nd generation tax-register wealth in column 1, and 3rd generation tax-register wealth in columns 2-4. Explanatory variables are tax-register wealth for parents and grandparents. All wealth variables are percentile ranked within birth cohort groups, and all regressions include birth cohort group dummies for all generations.

${ }^{*} p<0.10,{ }^{* *} p<0.05,{ }^{* * *} p<0.01$ 
Online Appendix Table 5: Wealth regressions, IHS and log transformed

\begin{tabular}{|c|c|c|c|c|}
\hline & 2nd generation & \multicolumn{3}{|c|}{ 3rd generation } \\
\hline & $(1)$ & $(2)$ & (3) & (4) \\
\hline Parents & $\begin{array}{c}\text { Panel A: IHS wealth } \\
0.221^{* * *} \\
(0.036)\end{array}$ & $\begin{array}{l}0.267^{* * *} \\
(0.036)\end{array}$ & & $\begin{array}{l}0.256^{* * *} \\
(0.037)\end{array}$ \\
\hline Grandparents & & & $\begin{array}{l}0.150^{* * *} \\
(0.048)\end{array}$ & $\begin{array}{c}0.082^{*} \\
(0.048)\end{array}$ \\
\hline $\mathrm{R}^{2}$ & 0.033 & 0.043 & 0.018 & 0.051 \\
\hline Parents & $\begin{array}{c}\text { Panel B: IHS wealth } \\
0.291^{* * *} \\
(0.048)\end{array}$ & $\begin{array}{l}\text { to all wit } \\
0.268^{* * *} \\
(0.037)\end{array}$ & ealth & $\begin{array}{c}0.257^{* * *} \\
(0.037)\end{array}$ \\
\hline Grandparents & & & $\begin{array}{l}0.199^{* * *} \\
(0.063)\end{array}$ & $\begin{array}{c}0.112^{*} \\
(0.064)\end{array}$ \\
\hline $\mathrm{R}^{2}$ & 0.033 & 0.042 & 0.018 & 0.051 \\
\hline Parents & $\begin{array}{c}\text { Panel C: IHS wealth } \\
0.538^{* * *} \\
(0.090)\end{array}$ & $\begin{array}{l}000 \text { to all } \\
0.265^{* * *} \\
(0.037)\end{array}$ & wealth & $\begin{array}{l}0.252^{* * *} \\
(0.038)\end{array}$ \\
\hline Grandparents & & & $\begin{array}{l}0.386^{* * *} \\
(0.119)\end{array}$ & $\begin{array}{l}0.234^{* *} \\
(0.119)\end{array}$ \\
\hline $\begin{array}{l}\mathrm{R}^{2} \\
N\end{array}$ & $\begin{array}{l}0.032 \\
1147\end{array}$ & $\begin{array}{l}0.041 \\
2100\end{array}$ & $\begin{array}{l}0.019 \\
2100\end{array}$ & $\begin{array}{l}0.049 \\
2100\end{array}$ \\
\hline Parents & $\begin{array}{c}\text { Panel D: Log wealth } \\
0.175^{* * *} \\
(0.046)\end{array}$ & $\begin{array}{l}0.384^{* * *} \\
(0.055)\end{array}$ & & $\begin{array}{l}0.318^{* * *} \\
(0.056)\end{array}$ \\
\hline Grandparents & & & $\begin{array}{l}0.244^{* * *} \\
(0.047)\end{array}$ & $\begin{array}{c}0.168^{* * *} \\
(0.047)\end{array}$ \\
\hline $\begin{array}{l}\mathrm{R}^{2} \\
N\end{array}$ & $\begin{array}{c}0.072 \\
415\end{array}$ & $\begin{array}{c}0.119 \\
571\end{array}$ & $\begin{array}{c}0.082 \\
571\end{array}$ & $\begin{array}{c}0.153 \\
571\end{array}$ \\
\hline Parents & $\begin{array}{c}\text { Panel E: Ranked we } \\
0.313^{* * *} \\
(0.094)\end{array}$ & $\begin{array}{c}\text { mple (Pan } \\
0.289^{* * *} \\
(0.044)\end{array}$ & & $\begin{array}{l}0.275^{* * *} \\
(0.043)\end{array}$ \\
\hline Grandparents & & & $\begin{array}{l}0.345^{* * *} \\
(0.079)\end{array}$ & $\begin{array}{l}0.192^{* *} \\
(0.083)\end{array}$ \\
\hline $\begin{array}{l}\mathrm{R}^{2} \\
N\end{array}$ & $\begin{array}{c}0.063 \\
415\end{array}$ & $\begin{array}{c}0.177 \\
571\end{array}$ & $\begin{array}{c}0.111 \\
571\end{array}$ & $\begin{array}{c}0.228 \\
571\end{array}$ \\
\hline
\end{tabular}

Notes: Standard errors in parentheses are clustered on family. Dependent variable is 2nd generation tax-register wealth in column 1, and 3rd generation tax-register wealth in columns 2-4. Explanatory variables are tax-register wealth for parents and grandparents. Wealth variables are inverse hyperbolic sine transformed in panels A-C. In panel B, 10 has been added to all zeroes in 1st generation wealth before transforming, and in panel C 1000 has been added. In panel $\mathrm{D}$, all wealth variables are log transformed, and panel $\mathrm{E}$ shows percentile rank regressions for the same sample as the log regressions in panel D. All regressions include quadratic birth year controls for both generations in panels A-D, and birth cohort group dummies of all generations in panel E.

${ }^{*} p<0.10,{ }^{* *} p<0.05,{ }^{* * *} p<0.01$ 
Online Appendix Table 6: Imputed regressions, sensitivity analysis

\begin{tabular}{lcc}
\hline & $(1)$ & $(2)$ \\
& Censored & Imputed \\
\hline Parents & $0.441^{* * *}$ & $0.386^{* * *}$ \\
& $(0.023)$ & $(0.026)$ \\
\hline$N$ & 2100 & 2094 \\
\hline
\end{tabular}

Notes: Standard errors in parentheses are clustered on family. Dependent variable is 3rd generation tax-register wealth. Explanatory variables are tax-register wealth for parents. In column 1 parental wealth has been artificially censored to mimic the censoring in 1st generation wealth, and in column 2 the censored values have been imputed (see text for details). All wealth variables are percentile ranked within birth cohort groups, and all regressions include birth cohort group dummies for both generations. $p<0.10,{ }^{* *} p<0.05,{ }^{* * *} p<0.01$

Online Appendix Table 7: Wealth regressions at younger ages

\begin{tabular}{lccc}
\hline & $(1)$ & $(2)$ & $(3)$ \\
\hline Parents & $0.261^{* * *}$ & & $0.242^{* * *}$ \\
& $(0.026)$ & & $(0.027)$ \\
Grandparents & & $0.154^{* * *}$ & $0.080^{* * *}$ \\
& & $(0.030)$ & $(0.030)$ \\
\hline $\mathrm{R}^{2}$ & & 0.040 & 0.099 \\
$N$ & 0.080 & 2099 & 2099 \\
\hline
\end{tabular}

Notes: Standard errors in parentheses are clustered on family. Dependent variable is 3rd generation tax-register wealth measured in 1985, 1988, and 1991, so that these individuals are around age 30 when their wealth is measured. Explanatory variables are tax-register wealth for parents and grandparents. All wealth variables are percentile ranked within birth cohort groups, and all regressions include birth cohort group dummies of all generations.

${ }^{*} p<0.10,{ }^{* *} p<0.05,{ }^{* * *} p<0.01$

Online Appendix Table 8: Controlling for inheritance fractional polynomial

\begin{tabular}{lcccc}
\hline & $(1)$ & $(2)$ & $(3)$ & $(4)$ \\
\hline Parents' wealth & $0.251^{* * *}$ & $0.0912^{* *}$ & $0.0894^{* *}$ & $0.0753^{*}$ \\
& $(0.0393)$ & $(0.0448)$ & $(0.0449)$ & $(0.0453)$ \\
\hline Polynomial terms & 0 & 1 & 2 & 3 \\
$\mathrm{R}^{2}$ & 0.079 & 0.140 & 0.141 & 0.146 \\
$N$ & 809 & 809 & 809 & 809 \\
\hline
\end{tabular}

Standard errors in parentheses are clustered on family. Dependent variable is percentile ranked 2nd generation 1991 tax-register wealth. Explanatory variables are percentile ranked parental tax-register wealth and a fractional polynomial in average inheritance received. All regressions include birth cohort group dummies for both generations and a quadratic in average parental year of death.

${ }^{*} p<0.10,{ }^{* *} p<0.05,{ }^{* * *} p<0.01$ 
Online appendix table 9: Inheritance regressions, sensitivity analyses

\begin{tabular}{|c|c|c|c|c|c|c|}
\hline & \multicolumn{3}{|c|}{ One or two parents bequeathing } & \multicolumn{3}{|c|}{ Two parents bequeathing } \\
\hline & (1) & $(2)$ & (3) & $(4)$ & $(5)$ & (6) \\
\hline & \multicolumn{6}{|c|}{ Panel A: Bottom-censored inheritance } \\
\hline Parents' wealth & & $\begin{array}{l}0.262^{* * *} \\
(0.039)\end{array}$ & $\begin{array}{l}0.121^{\text {*** }} \\
(0.044)\end{array}$ & & $\begin{array}{l}0.310^{* * *} \\
(0.054)\end{array}$ & $\begin{array}{l}0.151^{* *} \\
(0.067)\end{array}$ \\
\hline Inheritance & $\begin{array}{l}0.349^{* * *} \\
(0.037)\end{array}$ & & $\begin{array}{l}0.279^{* * *} \\
(0.044)\end{array}$ & $\begin{array}{l}0.346^{* * *} \\
(0.055)\end{array}$ & & $\begin{array}{l}0.249^{* * *} \\
(0.068)\end{array}$ \\
\hline $\mathrm{R}^{2}$ & 0.115 & 0.071 & 0.137 & 0.140 & 0.113 & 0.179 \\
\hline Parents' wealth & Panel B: & $\begin{array}{l}\text { decile in } \\
0.153^{* * *} \\
(0.045)\end{array}$ & $\begin{array}{l}\text { itance reg } \\
0.059 \\
(0.043)\end{array}$ & ons & $\begin{array}{l}0.204^{* * *} \\
(0.062)\end{array}$ & $\begin{array}{l}0.085 \\
(0.065)\end{array}$ \\
\hline Inheritance & $\begin{array}{l}0.245^{* * *} \\
(0.050)\end{array}$ & & $\begin{array}{l}0.210^{* * *} \\
(0.051)\end{array}$ & $\begin{array}{l}0.212^{* * *} \\
(0.053)\end{array}$ & & $\begin{array}{l}0.167^{* * *} \\
(0.055)\end{array}$ \\
\hline $\mathrm{R}^{2}$ & 0.087 & 0.047 & 0.108 & 0.144 & 0.101 & 0.184 \\
\hline$N$ & 809 & 809 & 809 & 386 & 386 & 386 \\
\hline
\end{tabular}

Notes: Standard errors in parentheses are clustered on family. Dependent variable is 2nd generation tax-register wealth. Explanatory variables are tax-register wealth for parents and total inheritance received from parents. In panel A, inheritance has been censored by setting the lowest values to zero, to mimic the censoring in parental wealth. Parents' wealth has been percentile ranked within birth cohort groups, and average inheritance has been percentile ranked within parental year of death groups. In panel B, all wealth and inheritance variables are dummy variables equal to one for individuals in the top 10 percent of the wealth distribution within their birth cohort (year of death for inheritances) group, and zero otherwise. All regressions include birth and death cohort group dummies corresponding to the included variables.

${ }^{*} p<0.10,{ }^{* *} p<0.05,{ }^{* * *} p<0.01$ 
Online appendix table 10: Inheritance regressions, CPI and GDP adjusted

\begin{tabular}{lccccc}
\hline & \multicolumn{2}{c}{ Main } & & \multicolumn{2}{c}{ Only two inheritances } \\
\cline { 2 - 3 } \cline { 5 - 6 } & CPI & GDP & & CPI & GDP \\
\hline Parents' wealth & 0.043 & -0.061 & & 0.031 & -0.089 \\
& $(0.042)$ & $(0.042)$ & & $(0.061)$ & $(0.062)$ \\
\hline $\mathrm{R}^{2}$ & 0.009 & 0.014 & & 0.033 & 0.037 \\
$N$ & 809 & 809 & & 386 & 386 \\
\hline
\end{tabular}

Notes: Standard errors in parentheses are clustered on family. Outcome variable is child wealth excluding inheritance, calculated as the sum of received inheritances that have been adjusted for inflation (column 1) or economic growth (column 2). In columns 3-4, only those who have received inheritances from both parents are included. All regressions include birth cohort group dummies for both generations.

${ }^{*} p<0.10,{ }^{* *} p<0.05,{ }^{* * *} p<0.01$ 
Online Appendix Table 11: Mediating variables regressions, child's wealth purged from inheritance

\begin{tabular}{lcccc}
\hline & $(1)$ & $(2)$ & $(3)$ & $(4)$ \\
\hline Parents' wealth & 0.018 & -0.005 & -0.020 & -0.017 \\
& $(0.044)$ & $(0.044)$ & $(0.044)$ & $(0.045)$ \\
Parents' earnings & & 0.017 & & -0.006 \\
& & $(0.041)$ & & $(0.042)$ \\
Parents' schooling & & 0.020 & 0.020 \\
& & & $(0.043)$ & $(0.044)$ \\
Own earnings & & $0.161^{* * *}$ & & $0.138^{* * *}$ \\
& & $(0.038)$ & & $(0.039)$ \\
Own schooling & & & $0.118^{* * *}$ & $0.071^{*}$ \\
& & & $(0.040)$ & $(0.041)$ \\
\hline $\mathrm{R}^{2}$ & & & 0.052 & 0.068 \\
$N$ & & & 782 & 782 \\
\hline
\end{tabular}

Notes: Standard errors in parentheses are clustered on family. Dependent variable is 2nd generation tax-register wealth purged from inheritances using the specification in column 3 of Table 6. Explanatory variables are parents' tax-register wealth, earnings, and schooling, and own earnings and schooling. All wealth variables are percentile ranked within birth cohort groups. Earnings is percentile ranked lifetime earnings, and schooling is percentile ranked years of completed schooling. All regressions include birth cohort group dummies for all included generations.

${ }^{*} p<0.10,{ }^{* *} p<0.05,{ }^{* * *} p<0.01$ 
Online Appendix Table 12: 3rd generation mediating variables regressions

\begin{tabular}{|c|c|c|c|c|c|c|}
\hline & $\begin{array}{c}(1) \\
\text { Wealth }\end{array}$ & $\begin{array}{c}(2) \\
\text { Earnings }\end{array}$ & $\begin{array}{c}(3) \\
\text { Schooling }\end{array}$ & $\begin{array}{c}(4) \\
\text { Wealth }\end{array}$ & $\begin{array}{c}(5) \\
\text { Wealth }\end{array}$ & $\begin{array}{c}(6) \\
\text { Wealth }\end{array}$ \\
\hline & \multicolumn{6}{|c|}{ Panel A: Regressions of 3rd generation on parents } \\
\hline Parents' wealth & $\begin{array}{c}0.395^{* * *} \\
(0.021)\end{array}$ & & & $\begin{array}{c}0.320^{* * *} \\
(0.023)\end{array}$ & $\begin{array}{c}0.330^{* * *} \\
(0.024)\end{array}$ & $\begin{array}{c}0.300^{* * *} \\
(0.024)\end{array}$ \\
\hline Parents' earnings & & $\begin{array}{c}0.234^{* * *} \\
(0.023)\end{array}$ & & $\begin{array}{c}0.031 \\
(0.023)\end{array}$ & & $\begin{array}{c}0.013 \\
(0.024)\end{array}$ \\
\hline Parents' schooling & & & $\begin{array}{c}0.390^{* * *} \\
(0.021)\end{array}$ & & $\begin{array}{c}0.005 \\
(0.023)\end{array}$ & $\begin{array}{l}-0.005 \\
(0.022)\end{array}$ \\
\hline Own earnings & & & & $\begin{array}{c}0.259^{* * *} \\
(0.020)\end{array}$ & & $\begin{array}{c}0.226^{* * *} \\
(0.021)\end{array}$ \\
\hline Own schooling & & & & & $\begin{array}{l}0.194^{* * *} \\
(0.022)\end{array}$ & $\begin{array}{c}0.116^{* * * *} \\
(0.023)\end{array}$ \\
\hline $\mathrm{R}^{2}$ & 0.171 & 0.072 & 0.172 & 0.238 & 0.204 & 0.247 \\
\hline$N$ & 2490 & 2490 & 2490 & 2490 & 2490 & 2490 \\
\hline \multicolumn{7}{|c|}{ Panel B: Regressions of 3rd generation on grandparents } \\
\hline Grandparents' wealth & $\begin{array}{l}0.170^{* * *} \\
(0.032)\end{array}$ & & & $\begin{array}{l}0.087^{* *} \\
(0.031)\end{array}$ & $\begin{array}{l}0.116^{* * *} \\
(0.031)\end{array}$ & $\begin{array}{c}0.079^{* * *} \\
(0.030)\end{array}$ \\
\hline Grandparents' earnings & & $\begin{array}{c}0.144^{* * *} \\
(0.027)\end{array}$ & & $\begin{array}{c}0.086^{* * *} \\
(0.027)\end{array}$ & & $\begin{array}{l}0.062^{* *} \\
(0.028)\end{array}$ \\
\hline Grandparents' schooling & & & $\begin{array}{l}0.189^{* * *} \\
(0.028)\end{array}$ & & $\begin{array}{c}0.020 \\
(0.029)\end{array}$ & $\begin{array}{l}-0.010 \\
(0.029)\end{array}$ \\
\hline Own earnings & & & & $\begin{array}{c}0.313^{* * *} \\
(0.022)\end{array}$ & & $\begin{array}{c}0.244^{* * *} \\
(0.024)\end{array}$ \\
\hline Own schooling & & & & & $\begin{array}{c}0.298^{* * *} \\
(0.024)\end{array}$ & $\begin{array}{c}0.199^{* * *} \\
(0.026)\end{array}$ \\
\hline $\mathrm{R}^{2}$ & 0.047 & 0.048 & 0.062 & 0.160 & 0.137 & 0.190 \\
\hline$N$ & 2000 & 2000 & 2000 & 2000 & 2000 & 2000 \\
\hline \multicolumn{7}{|c|}{$\begin{array}{l}\text { Panel C: Regressions of 3rd generation on parents and grand- } \\
\text { parents }\end{array}$} \\
\hline Parents' wealth & $\begin{array}{l}0.395^{* * *} \\
(0.026)\end{array}$ & & & $\begin{array}{l}0.322^{* * *} \\
(0.027)\end{array}$ & $\begin{array}{l}0.336^{* * *} \\
(0.027)\end{array}$ & $\begin{array}{l}0.304^{* * *} \\
(0.027)\end{array}$ \\
\hline Grandparents' wealth & $\begin{array}{c}0.036 \\
(0.031)\end{array}$ & & & $\begin{array}{l}-0.002 \\
(0.029)\end{array}$ & $\begin{array}{c}0.023 \\
(0.029)\end{array}$ & $\begin{array}{c}0.004 \\
(0.029)\end{array}$ \\
\hline Parents' earnings & & $\begin{array}{l}0.209^{* * *} \\
(0.027)\end{array}$ & & $\begin{array}{c}0.050^{*} \\
(0.027)\end{array}$ & & $\begin{array}{c}0.033 \\
(0.028)\end{array}$ \\
\hline Grandparents' earnings & & $\begin{array}{l}0.097^{* * *} \\
(0.027)\end{array}$ & & $\begin{array}{c}0.036 \\
(0.025)\end{array}$ & & $\begin{array}{c}0.033 \\
(0.026)\end{array}$ \\
\hline Parents' schooling & & & $\begin{array}{l}0.367^{* * *} \\
(0.026)\end{array}$ & & $\begin{array}{l}-0.002 \\
(0.026)\end{array}$ & $\begin{array}{l}-0.017 \\
(0.026)\end{array}$ \\
\hline Grandparents' schooling & & & $\begin{array}{l}0.074^{* * *} \\
(0.027)\end{array}$ & & $\begin{array}{l}-0.007 \\
(0.027)\end{array}$ & $\begin{array}{l}-0.022 \\
(0.027)\end{array}$ \\
\hline Own earnings & & & & $\begin{array}{l}0.248^{* * *} \\
(0.022)\end{array}$ & & $\begin{array}{c}0.211^{* * *} \\
(0.024)\end{array}$ \\
\hline Own schooling & & & & & $\begin{array}{l}0.211^{* * *} \\
(0.026)\end{array}$ & $\begin{array}{l}0.132^{* * *} \\
(0.027)\end{array}$ \\
\hline $\mathrm{R}^{2}$ & 0.193 & 0.094 & 0.196 & 0.263 & 0.237 & 0.275 \\
\hline$N$ & 1971 & 1971 & 1971 & 1971 & 1971 & 1971 \\
\hline
\end{tabular}

Notes: Standard errors in parentheses are clustered on family. Dependent variable is 3rd generation tax-register 
wealth in columns 1 and 3-6, earnings in column 2, and schooling in column 3. Explanatory variables are taxregister wealth, earnings, and schooling for parents and grandparents, and own earnings and schooling. All wealth variables are percentile ranked within birth cohort groups. Earnings is percentile ranked lifetime earnings, and schooling is percentile ranked years of completed schooling. All regressions include birth cohort group dummies for all included generations.

${ }^{*} p<0.10,{ }^{* *} p<0.05,{ }^{* * *} p<0.01$ 

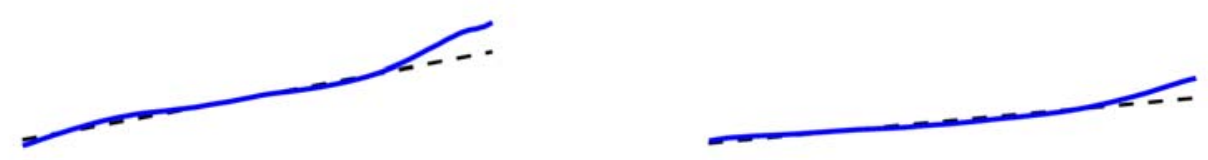

$0.75-$

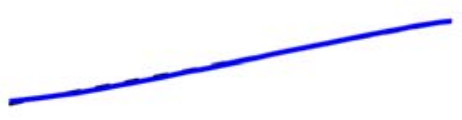

$0.25-$

$0.00-$

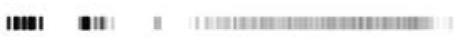

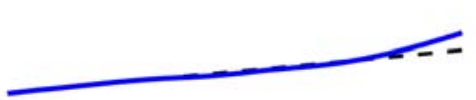

$0.75-$

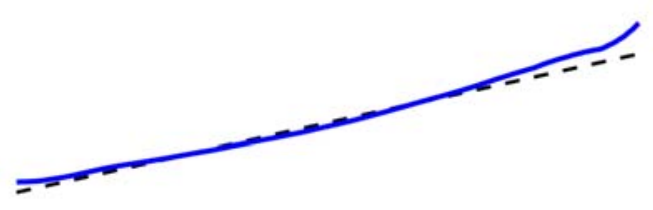

$0.25-$

$0.00-$

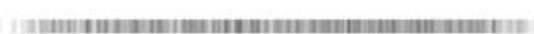

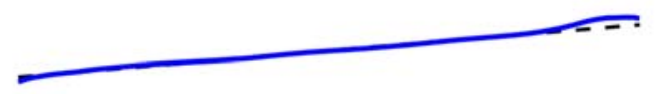

$0.75-$
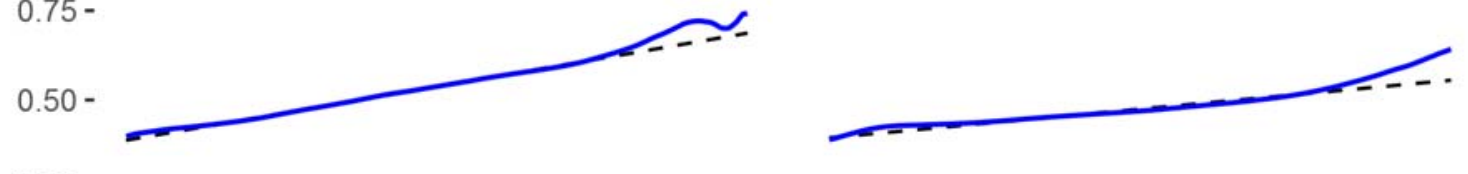

$0.25-$

\section{$0.00-$}

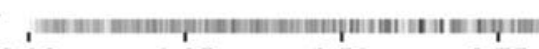

0.00

0.25

0.50

0.75

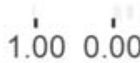

0.25

0.50

$0.75 \quad 1$ '.00

Online Appendix Figure 1: Kernel regressions, alternative measures for 1st generation

Notes: Solid lines show results from bivariate local linear kernel regressions using an Epanechnikov kernel and 0.12 bandwidth. The $\mathrm{x}$ axis shows ancestors' wealth percentile rank, and the $\mathrm{y}$ axis shows descendants' wealth percentile rank. The variables have been residualized by regressing out birth cohort dummies for both generations, and the residuals have been rescaled to have the same range as the original percentile ranked variables. Dashed lines show best linear fits, and the vertical lines along the bottom show the distribution of observations across. The first row repeats results from Figure 1 for reference, while subsequent rows show results corresponding to columns 1 and 3 in Table 3. 


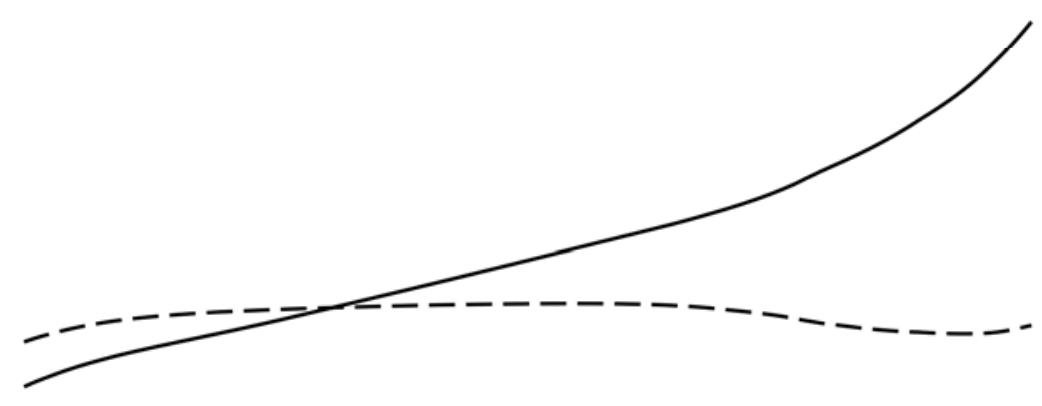

Online Appendix Figure 2: Purged inheritance kernel regressions

Notes: Lines show results from bivariate local linear kernel regressions using an Epanechnikov kernel and 0.2 bandwidth. The $\mathrm{x}$ axis shows parents' wealth percentile rank, and the $\mathrm{y}$ axis shows children's wealth percentile rank. Dependent variable is wealth for the solid line, and wealth net of inheritance for the dashed line, corresponds to columns 1 and 3 of Table 6 , panel B. The variables have been residualized by regressing out birth cohort dummies for both generations, and the residuals have been rescaled to have the same range as the original percentile ranked variables. 